\title{
Assessment of SMOS soil moisture retrieval parameters using tau-omega algorithms for soil moisture deficit estimation
}

\author{
Prashant K. Srivastava ${ }^{\mathrm{a}, \mathrm{b}, *}$, Dawei Han ${ }^{\mathrm{b}}$, Miguel A. Rico-Ramirez ${ }^{\mathrm{b}}$, Peggy O’Neill ${ }^{\mathrm{a}}$, Tanvir Islam ${ }^{\mathrm{c}}$, \\ Manika Gupta ${ }^{\mathrm{d}}$
}

${ }^{a}$ Hydrological Sciences (Code 617), ESSIC/NASA Goddard Space Flight Center, Greenbelt, MD 20771, USA

${ }^{\mathrm{b}}$ Water and Environment Management Research Centre, Department of Civil Engineering, University of Bristol, Bristol BS8 1TR, United Kingdom

${ }^{\mathrm{C}}$ CIRA/National Oceanic and Atmospheric Administration (NOAA), College Park, MD, USA

${ }^{\mathrm{d}}$ Water Resources, Department of Civil Engineering, Indian Institute of Technology, Delhi, India

\section{A R T I C L E I N F O}

\section{Article history:}

Received 20 January 2014

Received in revised form 18 July 2014

Accepted 28 July 2014

Available online 6 August 2014

This manuscript was handled by

Corrado Corradini, Editor-in-Chief

\section{Keywords:}

Tau-omega

Single channel algorithm

WRF-NOAH LSM

MODIS

Brightness temperature

Hydrological model

\begin{abstract}
S U M M A R Y
Soil Moisture and Ocean Salinity (SMOS) is the latest mission which provides flow of coarse resolution soil moisture data for land applications. However, the efficient retrieval of soil moisture for hydrological applications depends on optimally choosing the soil and vegetation parameters. The first stage of this work involves the evaluation of SMOS Level 2 products and then several approaches for soil moisture retrieval from SMOS brightness temperature are performed to estimate Soil Moisture Deficit (SMD). The most widely applied algorithm i.e. Single channel algorithm (SCA), based on $\tau-\omega$ is used in this study for the soil moisture retrieval. In $\tau-\omega$, the soil moisture is retrieved using the Horizontal $(H)$ polarisation following Hallikainen dielectric model, roughness parameters, Fresnel's equation and estimated Vegetation Optical Depth $(\tau)$. The roughness parameters are empirically calibrated using the numerical optimization techniques. Further to explore the improvement in retrieval models, modifications have been incorporated in the algorithms with respect to the sources of the parameters, which include effective temperatures derived from the European Center for Medium-Range Weather Forecasts (ECMWF) downscaled using the Weather Research and Forecasting (WRF)-NOAH Land Surface Model and Moderate Resolution Imaging Spectroradiometer (MODIS) land surface temperature (LST) while the $\tau$ is derived from MODIS Leaf Area Index (LAI). All the evaluations are performed against SMD, which is estimated using the Probability Distributed Model following a careful calibration and validation integrated with sensitivity and uncertainty analysis. The performance obtained after all those changes indicate that SCA-H using WRF-NOAH LSM downscaled ECMWF LST produces an improved performance for SMD estimation at a catchment scale.
\end{abstract}

Published by Elsevier B.V.

\section{Introduction}

The accurate estimation of soil moisture is important for understanding the Earth's hydrological cycle and ecosystem services (Cramer et al., 2001). It is a key variable in the water and energy exchanges that occur at the land-surface/atmosphere interface and responsible for the evolution of weather and climate over continental regions (Entekhabi et al., 2010; Mahfouf, 1991). Hence, global observations of the Earth's changing soil moisture are needed to enhance climatic prediction skills, weather forecasting, assessment of water quantity and quality, agricultural water

* Corresponding author. Address: Hydrological Sciences (Code 617), ESSIC/NASA Goddard Space Flight Center, Room No. G208, Building 33, Greenbelt, MD 20771, USA. Tel.: +1 301614 6384, mobile: +1 3013291010 .

E-mail addresses: prashant.k.srivastava@nasa.gov, prashant.just@gmail.com (P.K. Srivastava). management, crop productivity, mitigation of natural hazards such as landslides, flood prediction and drought monitoring (Srivastava et al., 2013b). Soil moisture is an integral component for rainfallrunoff models and designing water balance equations (Aubert et al., 2003; Merz and Plate, 1997).

Scientists started research on soil moisture remote sensing from mid 1970's shortly after the surge in satellite development (Laymon et al., 1999). Advances in satellite remote sensing have offered a variety of techniques for measuring soil moisture (Engman, 1990). Soil moisture can be estimated through ground based techniques such as from probe or gravimetric measurements with limitations that these are currently limited to specific locations, and hence do not represent the spatial distribution because soil moisture is highly variable both spatially and temporally (Srivastava, 2013; Wang and Qu, 2009). Several researchers have also shown that near surface soil moisture content can be 
measured by optical and thermal infrared remote sensing (Jackson, 1993; Owe et al., 2001; Schmugge et al., 1986; Scott and Bastiaanssen, 2003). For decades microwave remote sensing has proven its capability over optical remote sensing for soil moisture retrieval and that's the reason two dedicated space missions were proposed to provide global measurements of soil moisture. The first is from the European Space Agency, which launched the Soil Moisture and Ocean Salinity (SMOS) mission in November 2009 and the second, Soil Moisture Active and Passive (SMAP) mission planned by the National Aeronautics and Space Administration (NASA) to be launched by 2014.

The $\mathrm{L}$ band soil moisture can be retrieved by utilizing a radiative transfer model to convert brightness temperature from microwave radiometers to soil moisture using single/dual channel algorithms (Jackson et al., 1997). Most of the methods for L band soil moisture retrieval from passive radiometers are based on tau-omega rationale (de Jeu et al., 2014; Mladenova et al., 2014). The widely accepted methodology for soil moisture retrieval is based on inversion of geophysical model functions which is also currently used by SMOS (Jackson et al., 2002; Kerr et al., 2006, 2012). The other model such as Land Parameter Retrieval Model (LPRM) has been used by many researchers and well explored on high frequency microwave datasets (Liu et al., 2012; Su et al., 2011). The most widely used model for soil moisture retrieval from $L$ band is aingle channel algorithms (SCA) which uses $H$ and $V$ polarizations separately. Likewise as mentioned in Mladenova et al. (2014) both of the abovementioned soil moisture retrieval models i.e. LPRM and SCA are based on tau-omega algorithms utilizing similar radiative transfer equation given by Mo et al. (1982). However, suitability and reliability of these models for SMOS soil moisture retrieval for hydrological applications such for SMD estimation is still under question.

Previous studies have shown that the variation in soil moisture can be directly linked with land surface temperature (LST) and Normalized Difference Vegetation index (NDVI) (Goward et al., 2002; Sandholt et al., 2002). Some authors have also indicated the estimation of vegetation water content, an integral parameter for Vegetation Optical Depth (VOD), using satellite datasets such as Moderate Resolution Imaging Spectroradiometer (MODIS) Leaf Area Index (LAI) or NDVI (Kerr et al., 2012; Jackson et al., 2002). After development of optical sensors and mesoscale models such as WRF, a high resolution LST can be estimated from MODIS and ECMWF downscaling which could serve as a suitable choice for soil moisture retrieval using passive microwave data like SMOS. In this study, attempts have been made to synergistically combine the SMOS brightness temperature with the MODIS and Weather Research and Forecasting-NOAH Land Surface Model downscaled European Center for Medium-Range Weather Forecasts (ECMWF) LST for the soil moisture retrieval and subsequently use it for the SMD estimation. The ECMWF and MODIS have been selected among other operational optical satellites/datasets because of its suitable characteristics, such as daily temporal resolution and free near real time availability (Srivastava et al., 2013a; Thakur et al., 2012). The use of MODIS Leaf Area Index (LAI) is taken into account for Vegetation Water Content (VWC) estimation, which is found to be an integral parameter for Vegetation Optical Depth $(\tau)$. SMD is used in this study, not storage because the former is driven by necessity. As compared with storage, SMD has direct application to drought and flood. A number of agencies in UK use SMD as an indicator for predicting drought or dryness of the country such as UK Met office (www.metoffice.gov.uk/), Land Information System (LandIS) (http://www.landis.org.uk/services/ seismic.cfm), Centre for Ecology and Hydrology Wallingford (http: //www.ceh.ac.uk/data/nrfa/nhmp/evaporation_smd.html), UK. Secondly, many rainfall runoff models use SMD as a soil moisture accounting scheme (Beven and Wood, 1983; Croke and
Jakeman, 2004; Evans and Jakeman, 1998). Therefore, a better prediction of SMD using satellite based soil moisture such as SMOS or upcoming SMAP could be used for an improved discharge prediction.

Despite of number of studies in the technical literature domain there are still many research questions unanswered such as- how good is the SMOS soil moisture to estimate Soil Moisture Deficit (SMD)? How much will be the soil moisture retrieval performance for SMD estimation when WRF downscaled ECMWF LST is used in the place of MODIS LST as WRF using ECMWF can provide LST at hourly interval concurrent to SMOS overpass time $(6 \mathrm{am} / 6 \mathrm{pm})$, which is not possible with MODIS. Other important parameters are roughness factors which are difficult to obtain over large scale, presently they can be obtained either by field experiments or using land cover based look up table. Therefore, it is good to know the performance of the optimized roughness parameters for the soil moisture retrieval instead of using the default one as given in SMOS ATBD (Algorithm Theoretical Basis Document). To understand all these research questions, this study focuses on the following objectives (1) estimation of quality controlled SMD at a catchment scale through PDM rainfall runoff model; (2) evaluation of soil moisture retrieval parameters using SCA-H approach by utilizing effective temperatures derived from the European Center for Medium-Range Weather Forecasts (ECMWF) and Moderate Resolution Imaging Spectroradiometer (MODIS) land surface temperature (LST) separately and optimized roughness parameters (3) performance assessment of retrieved soil moisture for hydrological SMD estimation.

\section{Materials and methods}

\subsection{Study area}

The Brue catchment $\left(135.5 \mathrm{Km}^{2}\right)$ chosen as the study area, located in the south-west of England, $51.11^{\circ} \mathrm{N}$ and $2.47^{\circ} \mathrm{W}$ is influenced primarily by the temperate maritime type of climate (Fig. 1). It is a good experimental site for satellite, mesoscale model based and rainfall runoff modeling research because of low vegetation cover (mainly grass), a maintained meteorological and flow station, moderate topography, and availability of nearly all required datasets generally used for any hydrological application and quality controlled as compared to other U.K. catchments. The river gauging point of the catchment is located at Lovington. The average altitude of this catchment is $105 \mathrm{~m}$ AMSL. The ground observed data for this study are obtained from the NERC (Natural Environment Research Council, U.K.) for the given period. The meteorological datasets are provided by the British Atmospheric Data Centre (BADC) that includes wind, net radiation, surface temperature and dew point.

The soil texture data for the Brue catchment was obtained from Soil Survey and Land Research Centre (SSLRC), U.K. The observed hourly rain gauge and river flow data for this study were obtained from the Environment Agency (U.K.). The observed rainfall in the Brue catchment used in this study is based on the areal rainfall calculated by averaging 3 rain gauges using the automated Thiessen polygon method (Han and Bray, 2006). The Probability Distributed Model (PDM) model is implemented over this catchment to estimate the SMD using a two-year calibration period (1st February 2009 to 31st January 2011) and one-year for validation (1st February 2011 to 31st January 2012). For validation, SMD is taken into account for comparison with the SMOS retrieved soil moisture. The detailed information on PDM calibration, validation, sensitivity and uncertainty analysis over Brue is mentioned in Section 3.1 while a more detailed analysis is reported in (Srivastava et al., 2013a). 


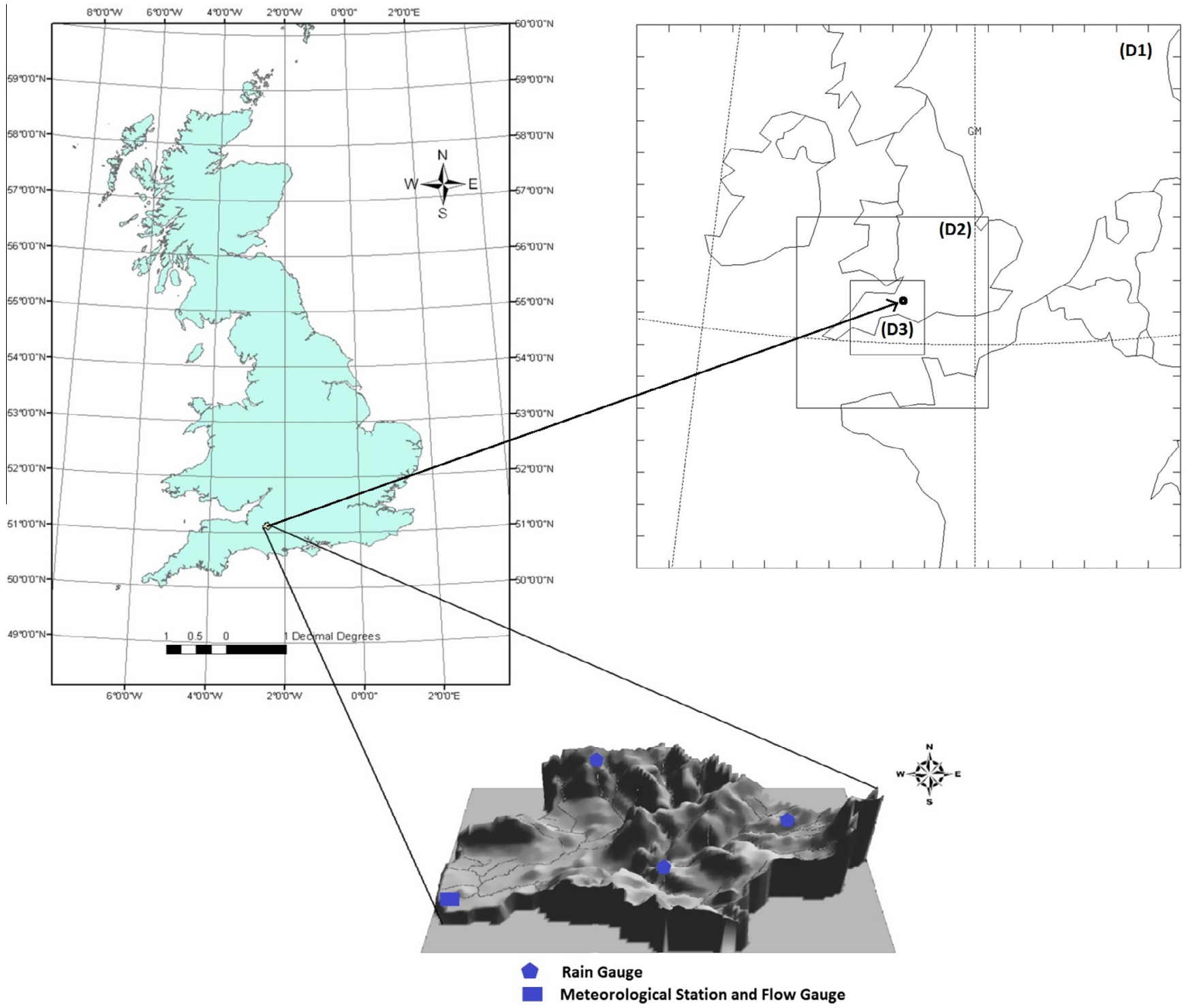

Fig. 1. Layout of the study area with meteorological station, rain, flow gauges and WRF domains.

\subsection{Dynamic datasets from ECMWF and MODIS}

\subsubsection{WRF-NOAH LSM downscaling using ECMWF datasets}

The latest Weather Research and Forecasting model coupled with NOAH Land Surface Model (LSM) is used in this study with the Advanced Research WRF (ARW) dynamic core version 3.1 (Powers, 2007; Schwartz et al., 2009) for LST estimation. The original LSM was developed at the Oregon State University (OSU) by Pan and Mahrt (1987) and modified by Chen et al. (1996). It includes an explicit canopy resistance formulation (Jacquemin and Noilhan, 1990) and a surface runoff scheme provided by Schaake et al. (1996). The soil water movement and flow in the NOAH LSM is governed by the mass conservation law and the diffusivity form of Richards' equation. A more detailed description of the WRF-NOAH LSM can be found in Chen and Dudhia (2001). The main physical options used in the WRF setup are the Dudhia shortwave radiation (Dudhia, 1989) and Rapid Radiative Transfer Model (RRTM) long wave radiation (Mlawer et al., 1997) with Lin microphysical parameterization; the Betts-Miller-Janjic Cumulus parameterization schemes; the Yonsei University (YSU) planetary boundary layer (PBL) scheme (Hu et al., 2010). The 3rd-order Runge-Kutta is used for the time integration while for spatial differencing scheme the 6th-order centered differencing scheme is used. The Arakawa C-grid is used for the horizontal grid distribution. The thermal diffusion scheme is used for the surface layer parameterization. The top and bottom boundary conditions chosen for the study are Gravity wave absorbing (diffusion or Rayleigh damping) and Physical or free-slip respectively. The Lambert conformal conic projection is used as the model horizontal coordinates. The vertical coordinate $\eta$ is defined as:

$\eta=\frac{\left(p_{r}-p_{t}\right)}{\left(p_{r s}-p_{t}\right)}$

where $p_{r}$ is pressure at the model surface being calculated; $p_{r s}$ is the pressure at the surface and $p_{t}$ is the pressure at the top of the model. In the vertical 28 terrain the following eta levels (eta levels $=1.000$, $0.990,0.978,0.964,0.946,0.922,0.894,0.860,0.817,0.766,0.707$, $0.644,0.576,0.507,0.444,0.380,0.324,0.273,0.228,0.188,0.152$, $0.121,0.093,0.0 .069,0.048,0.029,0.014,0.000$ ) from surface are used. These eta levels are used in this study because of their better representation of the topography (Black, 1994; Routray et al., 2010).

The WRF-NOAH LSM model is centered over the Brue catchment with three nested domains (D1, D2 and D3) with horizontal grid resolutions of $81 \mathrm{~km}, 27 \mathrm{~km}$ and $9 \mathrm{~km}$, in which the innermost 
domain (D3) is the area of interest. The smallest domain is taken into consideration firstly to avoid any spatial mismatch problem as it is closest to the catchment under study and secondly many researchers have found that the downscaled results are much improved (Heikkilä et al., 2011; Lo et al., 2008), hence higher resolution domain i.e. D3 is utilized in this study. The three domains consist of $18 \times 18,19 \times 19$, and $22 \times 22$ horizontal grids for Domains D1, D2 and D3 respectively. A two-way nesting scheme is used allowing information from the child domain to be fed back to the parent domain. The WRF model configuration used in this study is shown in Table 1 (Srivastava et al. (2013d). The WRF domains used in this study is shown in Fig. 1.

\subsubsection{MODIS satellite derived datasets}

The MODIS (Moderate Resolution Imaging Spectroradiometer) satellite products are used in this study for estimating soil moisture retrieval parameters such as $\tau$ and LST. The MODIS Level 3 $(\sim 5.6 \mathrm{~km})$ LST data are gridded uniformly across the globe with near real time availability and hence used in this study. In order to use the MODIS products, which are downloaded from MODIS LPDAAC https://lpdaac.usgs.gov/, and make it suitable for Brue catchment, we averaged the data using the Brue boundary using ENVI ITT version 4.8 and then determined the mean available MODIS observations over the Brue catchment. Both the SMOS and MODIS Terra are low Earth orbiting satellites and have local equatorial crossing times of approximately $6 \mathrm{am} / 6 \mathrm{pm}$ for SMOS, and 10:30 pm/10:30 am for Terra, in ascending/descending nodes (Sánchez-Ruiz et al., 2014). In this study, SMOS descending passes are combined with MODIS Terra ascending passes. It is therefore assumed that the soil moisture pattern is spatially persistent for a few hours before and after the SMOS overpass (Sánchez-Ruiz et al., 2014). Further, it is also useful to mention over here that a significant correlation was observed between LST and SMOS soil moisture in previous study over the same site by Srivastava et al. (2013a), hence we assume that the LST will not change much with

Table 1

WRF model configuration.

\begin{tabular}{|c|c|}
\hline Initial conditions & Three-dimensional real-data $\left(1^{\circ} \times 1^{\circ} \mathrm{FNL}\right)$ \\
\hline Map projection & Lambert \\
\hline \multirow{2}{*}{$\begin{array}{l}\text { Central point of } \\
\text { domain }\end{array}$} & Central latitude: $51.11^{\circ} \mathrm{N}$ \\
\hline & Central longitude: $2.47^{\circ} \mathrm{W}$ \\
\hline Domain & Three domains \\
\hline $\begin{array}{c}\text { Horizontal grid } \\
\text { distribution }\end{array}$ & Arakawa C-grid \\
\hline $\begin{array}{l}\text { Horizontal grid } \\
\quad \text { distance }\end{array}$ & Domain $3(9 \mathrm{~km})$ \\
\hline NCEP time interval & $6 \mathrm{~h}$ \\
\hline Model output & Hourly \\
\hline Nesting & 2 way \\
\hline Time integration & 3rd-order Runge-Kutta \\
\hline $\begin{array}{l}\text { Spatial differencing } \\
\text { scheme }\end{array}$ & 6th-order centered differencing \\
\hline $\begin{array}{l}\text { Lateral boundary } \\
\text { condition }\end{array}$ & Specified options for real-data \\
\hline $\begin{array}{l}\text { Top boundary } \\
\text { condition }\end{array}$ & $\begin{array}{l}\text { Gravity wave absorbing (diffusion or Rayleigh } \\
\text { damping) }\end{array}$ \\
\hline $\begin{array}{l}\text { Bottom boundary } \\
\text { condition }\end{array}$ & Physical or free-slip \\
\hline Microphysics & Lin \\
\hline Radiation scheme & Dudhia's short wave radiation/RRTM long wave \\
\hline $\begin{array}{l}\text { Surface layer } \\
\text { parameterization }\end{array}$ & Thermal diffusion scheme \\
\hline $\begin{array}{l}\text { Cumulus } \\
\text { parameterization } \\
\text { schemes }\end{array}$ & Betts-Miller-Janjic \\
\hline PBL parameterization & YSU scheme \\
\hline Vertical coordinate & $\begin{array}{l}\text { Terrain following hydrostatic pressure coordinate } \\
\text { ( } 28 \text { sigma levels up to } 1 \mathrm{hPa} \text { ) }\end{array}$ \\
\hline
\end{tabular}

depth for the effective soil moisture retrieval. Ideally, the temperature of the soil moisture sampling depth should be same as used to normalize the satellite observations, but it is not always possible in real environmental conditions (Owe et al., 2001). Moreover, there are rare satellite based LST products available exactly concurrent to SMOS overpass time and this is one of the major limitations in the soil moisture retrievals using MODIS datasets. Nevertheless, it can be used because of its near real time global availability and easy data processing. To overcome this limitation dynamical downscaling model (WRF) is used to estimate the LST using ECMWF global datasets concurrent to SMOS overpass time. For testing the retrieval algorithms, WRF downscaled ECMWF and MODIS land surface temperature (LST) products with a multitude of SMOS soil moisture are used separately with each algorithms.

The other important dynamic dataset that is very important in soil moisture retrieval is Leaf Area Index (LAI) which has been derived from MODIS LAI (MOD15) product. The MOD15 was developed jointly by Boston University, the University of Montana and NASA Goddard Space Flight Center. The temporal frequency of MOD15 is every 8th day as the reflectance and ancillary data on surface characteristics such as land cover type, background datasets, and other weather parameters etc are mostly available at this interval. As the data is not available daily and it is assumed that the minimal changes occur within 8 days in LAI, hence a constant forcing value is taken for every 8 days period.

\subsubsection{SMOS datasets}

The SMOS was launched by European Space Agency (ESA) on 2nd November 2009. The MIRAS instrument in the SMOS satellite acquiring data at the frequency of $1.4 \mathrm{GHz}$ ( $\mathrm{L}$-band), is a dual polarized 2-D interferometeric radiometer designed to provide global information on surface soil moisture with an accuracy of $4 \%$ (Kerr et al., 2001). In this study, SMOS Level 2 product and Level 1C SMOS Brightness temperature is used. The SMOS products are defined on the ISEA4H9 grid, i.e. Icosahedral Snyder Equal Area projection with aperture 4, resolution 9 and its shape of cells as hexagon (Pinori et al., 2008). The spatial resolution of the instrument is $\sim 40 \mathrm{~km}$ with the brightness temperature retrieval unit in Kelvin. Each point (or node) of this grid is known as a DGG (Discrete Global Grid) with fixed coordinates and is assigned with an identificator the "DGG Id".

In this study the brightness temperatures are retrieved at the incidence angle $42.5^{\circ}$ which is then used for the soil moisture retrieval. For the comparison between the catchment SMD and soil moisture, the SMOS brightness temperature pixel centred over the catchment is extracted and considered for the subsequent analysis. All the outputs of SMOS level 2 products were also retrieved at $42.5^{\circ}$ and to make soil moisture retrieval from brightness temperature consistent to SMOS level 2, all the soil moisture observations are retrieved at this angle only. This angle is chosen because SMOS has the best temporal coverage at $42.5^{\circ}$. This angle is obtained by linear interpolation of all TB acquired at an angle between $37.5^{\circ}$ and $47.5^{\circ}$ to $42.5^{\circ}$ (Kerr et al., 2012). The Beam 4.9 package with SMOS 2.1.3 plugin is used for all the data extraction. Most of the datasets extracted here are through growing season (most of the summer) and in clear sky conditions. The other soil moisture retrieval parameters specifically the MODIS LST, LAI are also found available during this period without any contamination.

\subsection{Land use/land cover, soil texture and DEM}

Land Use/Land Cover (LULC) analysis is vital for understanding the soil moisture retrieval algorithm development. The most popular Landsat TM is used in this study for the identification of land use/land cover. The Landsat TM images used in this study are acquired from www.usgs.gov.in with nearly $0 \%$ cloud cover over 
the region. The sophisticated Artificial Neural Network is used in this study for the derivation of LULC because of its better performance compared with other classification techniques (Srivastava et al., 2012b). The neural network classifier used was a layered feed-forward model in ENVI (Environment for Visualizing Images) version 4.8 (ITT Visual Information Solutions SA) with standard back propagation for supervised learning. The ANN weights were initialized using a uniform distribution. Learning rate was set to 100 for the hidden layer and 0.01 for the output layer, while stopping criterion is fixed to 0.001 . The typical logistic activation function can be expressed as Eq. (2) (Islam et al., 2014):

$o_{j}=1 /\left(1+e^{-\lambda \text { net }_{j}}\right)$

where $o_{j}$ is the output of external input $j, \lambda$ is a gain factor. The term net $_{j}$ can be computed using Eq. (3) (Islam et al., 2014):

net $_{j}=\sum_{i} w_{j i} o_{i}$

where $w_{j i}$ is the weight of interconnection channel to unit $j$ from unit $i$ and $o_{i}$ is the output of external unit $i$.

Land use/land cover of the area indicates that the most of the catchment is pasture land (94.34\%), with a few patches of forest (3.48\%) and urban areas (2.18\%). There are some patches of woodland in the higher eastern part of the catchment. It is a predominantly rural catchment with spring-fed headwaters rising in the Mendip Hills and Salisbury Plain (Fig. 2(a)). The DEM data used in this study are obtained from Digimap, an EDINA service (data library service at the University of Edinburgh) delivering Ordnance Survey map data to the higher education in the U.K. The data is derived from an ordnance Survey data product available in LandForm PANORAMA data at a 1:50000 scale DEM form. The DEM on a $50 \mathrm{~m}$ grid scale is then generated using the ArcGIS 9.3, shown in Fig. 2(b). Most of the area shows a modest relief and hence can be characterized as a non-complex topography area. A high resolution $100 \mathrm{~m}$ soil texture map for the Brue catchment has been obtained from the Soil Survey and Land Research Centre (SSLRC) (Fig. 2(c)). SSLRC datasets can be obtained through LandIS, which is the national computerised database system for soil and related land information in England and Wales, U.K. The distribution of soil from SSLRC maps indicates that the most of the area comprises of clayey soil type (49\%) followed by coarse loam $29 \%$ and silt $21 \%$.

\subsection{Single channel algorithms using tau-omega $(\tau-\omega)$}

The generalized Radiative Transfer Equation (RTE) in terms of all main factors can be expressed as given by Mo et al. (1982):

$T B_{P}=T B_{a t u}+T B_{s p} \exp \left(-\tau_{a t u}\right)+\left(T B_{a t d}+T B_{s k} \exp \left(-\tau_{a t d}\right)\right) r_{s p} \exp \left(-\tau_{a t u}\right)$

where " $p$ " subscript indicates the polarisation ( $H$ or $V$ ). The atmospheric opacities $\tau_{a t u}$ and $\tau_{\text {atd }}$ are the upward and downward path attenuating constituents, $T B_{s k}$ is the sky background, $r_{s p}$ is surface reflectivity, $T B_{a t d}$ and $T B_{a t u}$ are downward and upward atmospheric radiation components respectively. The signal measured by a passive microwave sensor at L-band can be expressed as a function of soil moisture, vegetation optical depth and effective surface temperature.

The surface characteristics, like soil texture and land use, can be obtained from static maps while others, like temperature are obtained from ECMWF reanalysis datasets or by using optical remote sensing such as MODIS. The algorithm presented here is for the surfaces having low vegetation. The area is considered to be a short vegetation area because it is mostly occupied by pasture land. At $\mathrm{L}$ band, the approximated form of RTE is considered as $\tau-\omega$ model. This model is based on two parameters i.e. the vegetation optical depth, $\tau$ and the vegetation scattering albedo, $\omega$ that are used to parameterize the vegetation attenuation properties and the scattering effects within the vegetation layer. The low vegetation $\tau-\omega$ model can be expressed as:

$T B_{P}=\left(1-\omega_{p}\right)\left(1-\gamma_{p}\right)\left(1+\gamma_{p} r_{g p}\right) T_{c}+\left(1-r_{g p}\right) \gamma_{p} T_{g}$

where $T_{g}$ and $T_{c}$ are the effective soil and vegetation temperatures, $r_{g p}$ is the soil reflectivity, $\omega_{p}$ the single scattering albedo, $\gamma_{p}$ the vegetation attenuation factor. The last term can be computed from the optical depth $\tau_{p}$ as:

$\gamma_{p}=\exp \left(-\tau_{p} / \cos \theta\right)$

For surface temperature, it is assumed that effective soil $\left(T_{g}\right)$ and vegetation $\left(T_{c}\right)$ temperatures are approximately equal to a single value $T_{g c} \approx T_{c} \approx T_{g}$. An estimate of an effective composite temperature $T_{g c}$ (including both soil and vegetation media) could be derived by the following equation:

$T_{g c}=A_{t} T_{c}+\left(1-A_{t}\right) T_{g}$

where $A_{t}=B_{t}\left(1-\exp \left(\tau_{N A D}\right)\right)$ following the condition: $0 \leqslant A t \leqslant 1$.

Where $\tau_{N A D}$ VOD at nadir. For low vegetation the coefficient $B_{t}$ can be replaced by the default value of $B_{t}=1.7$. For the scattering effects at L-band, the value of the single scattering albedo, $\omega$ is found to be rather low and sometimes assumed equal to 0.05 . To model the optical depth, $\tau_{p}$, several studies found that $\tau_{p}=b_{p} \times V W C$ where VWC is the vegetation water content and $b_{p}$ is a factor which is mainly dependent on the frequency, the canopy type, and the vegetation dielectric constant (Jackson and Schmugge, 1991).

At $1.4 \mathrm{GHz}$, a value of $b_{p}=0.12 \pm 0.03$ was found to be representative of low vegetation and also, recent studies found good correlations between $\tau_{p}$ and LAI (Kerr et al., 2012). Hence in this study LAI based $\tau_{p}$ is taken into account (Kerr et al., 2012). The VWC from LAI can be estimated following the approach developed by Wigneron et al. (2006, 2007). For herbaceous vegetation, VWC was linearly related to the Leaf Area Index and could be estimated from global LAI data given by the existing maps derived from remote sensing observations such as from MODIS. An analysis made over agricultural crops from the Institut National De La Recherche Agronomique (INRA) data sets has shown that the VWC/LAI ratio is about $0.5 \mathrm{~kg} / \mathrm{m}^{2}$ (Wigneron et al., 2006) when the vegetation is well-developed. Hence, in this study the VWC is taken equivalent to 0.5 times of LAI. After estimating the VWC, $\tau_{p}$ is determined with the value of $b_{p}$ equal to 0.13 . Soil reflectivity is highly dependent on soil and vegetation characteristics represented by the roughness parameter. The parameters that characterize the roughness are known as the $h$ and $Q$ parameters and quite difficult to obtain over a terrain. The roughness parameters ( $h$ and $Q$ ) are obtained by optimization using the $\tau-\omega$ model following the Levenberg Marquardt (LM) algorithm and by maximizing the correlation between SMD and soil moisture.

\subsection{PDM and soil moisture deficit}

The PDM model from CEH Wallingford is employed as a rainfall runoff simulation model in the case study, as it is capable of accounting for soil moisture in the system with an appropriate time step and inputs of data required for use in hydrological modeling. The PDM has been widely applied throughout the world for runoff prediction and currently in use for both operational and design purposes (Bell and Moore, 1998). It is under the category of lumped rainfall-runoff model capable of representing a variety of catchment-scale hydrological behaviors and requires only rainfall and reference evapotranspiration (ETo) for discharge prediction (Liu and Han, 2013). The model conceptual structural work flow of 

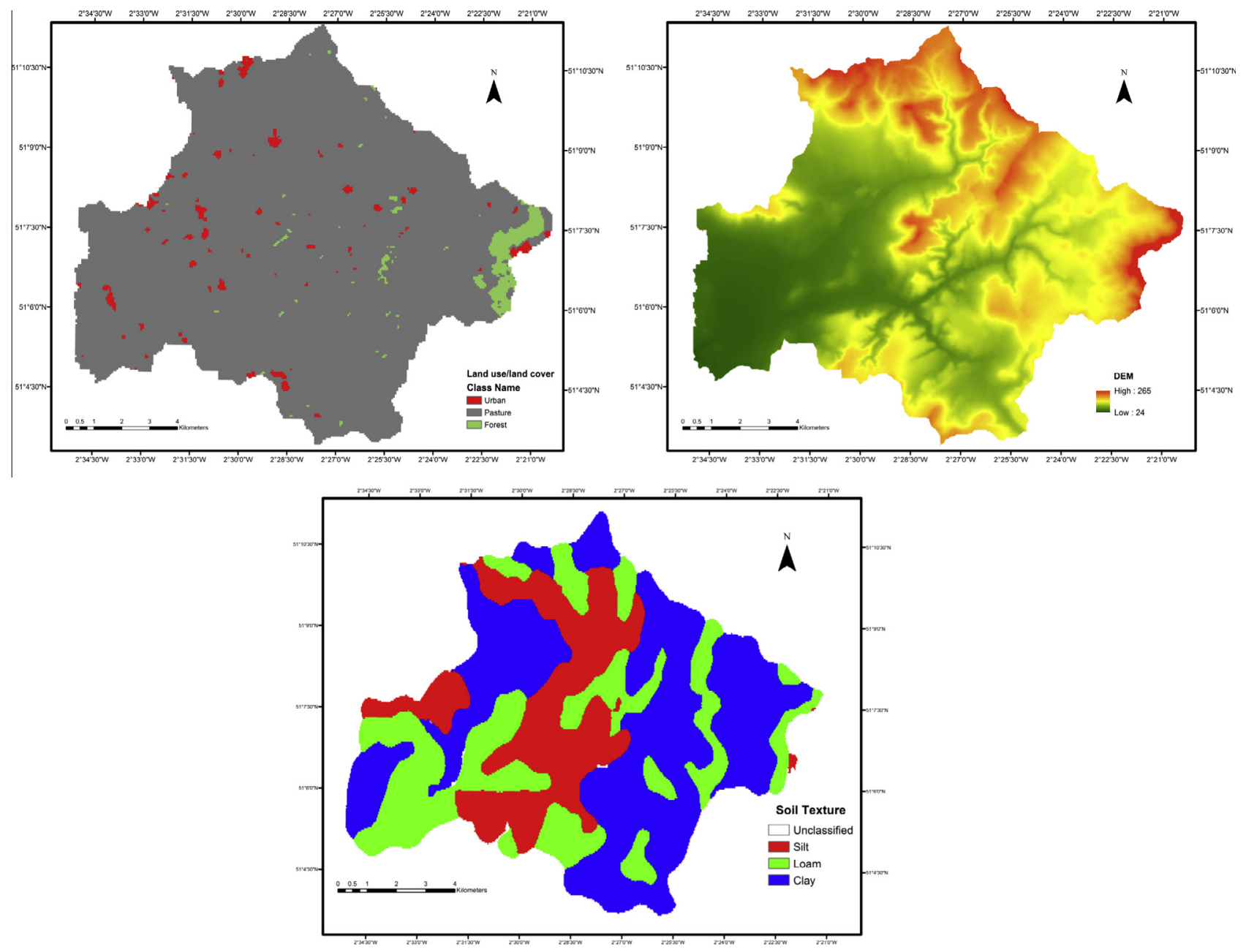

Fig. 2. Derived LULC (a), DEM (b) and soil texture (c).

PDM is depicted through Fig. 3. In this study, the PDM is used for SMD estimation through its moisture deficit routine (Moore, 2007):

$\frac{E_{i}^{\prime}}{E_{i}}=1-\left\{\frac{\left(S_{\max }-S(t)\right)}{S_{\max }}\right\}^{b_{e}}$

where $\frac{E_{i}^{\prime}}{E_{i}}$ is the ratio of actual ET to potential ET; and $\left(S_{\max }-S(t)\right)$ is Soil Moisture Deficit; $b_{e}$ is an exponent in the actual evaporation function; $S_{\max }$ is the total available storage and $S(t)$ is the storage at a particular time $t$. The model structure of PDM is further discussed in (Moore, 2007). The PDM model parameters available in PDM are shown in Table 2.

Sensitivity analysis (SA) and uncertainty analysis (UA) are considered to be an important tool in hydrological predictions (Blasone et al., 2008; Zheng and Keller, 2007). It has gained popularity in the hydrological community (Beven and Binley, 2006; Srivastava et al., 2013e; Yatheendradas et al., 2008) to explore the high dimensional parameter spaces, structural uncertainty and also to understand the sources of uncertainty. As hydrological models are increasingly being used, it is now very important for these models to pass through a rigorous and careful calibration and uncertainty analysis (Jin et al., 2010; Yang et al., 2008) and thus facilitate a good modeling practice for hydrological predictions. Hence, to test the quality of PDM predictions, it is integrated with Bayesian based Generalised Likelihood Uncertainty Estimation (GLUE). The main advantage with the GLUE parameter uncertainty is that it takes into account all sources of uncertainties either explicitly or implicitly (Beven and Binley, 2006; Zheng and Keller, 2007). After a rigorous and careful calibration, the SMD datasets are predicted and used for the subsequent analysis. The details of the outputs are mentioned in Section 3.1.

\subsection{Performance analysis}

In this study the SMOS soil moisture retrieved using the abovementioned models is compared with the PDM SMD. Although there are many statistics available, five of them (Nash Sutcliffe Efficiency (NSE) (Nash and Sutcliffe, 1970), Square of correlation $\left(R^{2}\right)$, Root Mean Square Error (RMSE), Standard Deviation (SD) and Correlation $(r)$ are used in this study. NSE is used as an objective function for PDM calibration and validation because it is the most widely used criterion for checking the efficiency of the hydrological models. Many authors compared the performance of different performance indices in hydrological modeling and indicated that using NSE generally is more reliable than using any other indices (McCuen et al., 2006; Krause et al., 2005). Hence, the performance of the PDM model is judged by the NSE coefficients as an objective indicator. It is based on the sum of the absolute squared differences 


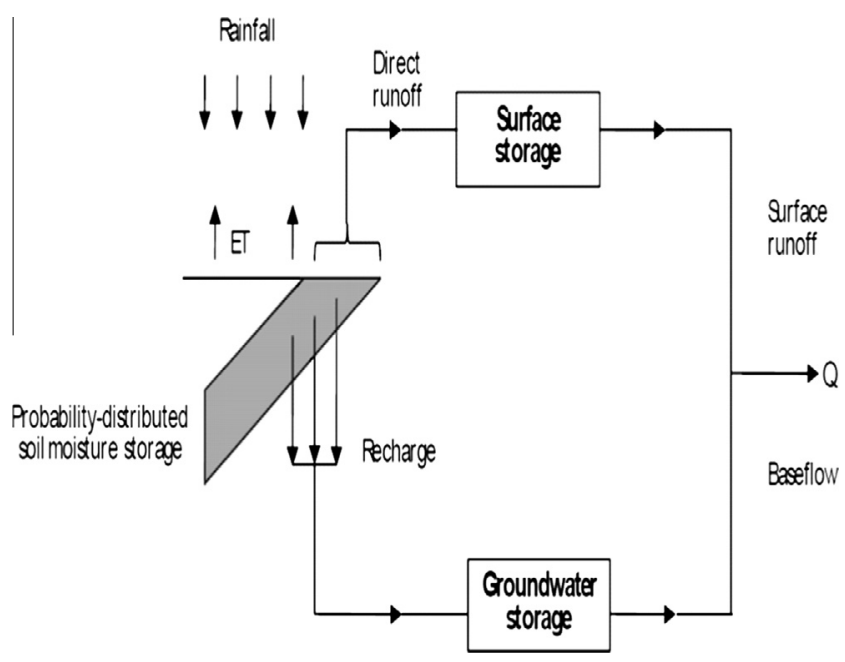

Fig. 3. The workflow of the PDM rainfall runoff model (Moore, 2007). between the simulated and observed values normalised by the variance of the observed values during the investigation period. The Nash-Sutcliffe Efficiency (NSE) is calculated using:

$$
\mathrm{NSE}=1-\frac{\sum_{i=1}^{n}\left[y_{i}-x_{i}\right]^{2}}{\sum_{i=1}^{n}\left[x_{i}-\bar{x}_{i}\right]^{2}}
$$

where $x_{i}$ is observed flow and $y_{i}$ is simulated flow.

The correlation, RMSE and SD are expressed in the form of Taylor diagram (Taylor, 2001) for SMD prediction derived using regression models. In a Taylor diagram, instead of using RMSE directly, it uses a plot in the form of various sectors represented as centered root-mean-square difference. It provides a way of graphically summarizing how closely a pattern matches observations. The similarities between two patterns are quantified in terms of their correlation, their centered root-mean-square difference and the amplitude of their variations (represented by their standard deviations). The circle mark in the $x$-axis, called reference point, represents the perfect fit between model results and data. The position of the labels, representing the results of the different

Table 2

The PDM model parameters.

\begin{tabular}{|c|c|c|c|c|}
\hline Symbol & Units & Model parameter & Optimum value & Range \\
\hline$f_{c}$ & none & Rainfall factor & 0.99 & $0.5-30$ \\
\hline$C_{\min }$ & $\mathrm{mm}$ & Minimum store capacity & 0 & 0.00 \\
\hline$C_{\max }$ & $\mathrm{mm}$ & Maximum store capacity & 129.70 & $50-500$ \\
\hline$b$ & none & $\begin{array}{l}\text { Exponent of pareto distribution controlling } \\
\text { spatial variability of store capacity }\end{array}$ & 0.46 & $0.2-1.5$ \\
\hline$b_{e}$ & none & Exponent in actual evaporation function & 7.4 & $1-10$ \\
\hline$k_{1}$ and $k_{2}$ & $\mathrm{~h}$ & Time constants of cascade of two linear reservoirs & $\begin{array}{l}k_{1}=6.61 \\
k_{2}=6.08\end{array}$ & $\begin{array}{l}k_{1}=1.0-20 \\
k_{2}=1.0-20\end{array}$ \\
\hline$k_{b}$ & $\mathrm{~h} \mathrm{~mm} \mathrm{~m}^{p-1}$ where $p$ is the store exponent & Base flow time constant & 39.80 & $5-100$ \\
\hline$k_{g}$ & $\mathrm{~h} \mathrm{~mm} \mathrm{mg}-1^{\mathrm{bg}}$ & Groundwater recharge time constant & 50,000 & $10,000-500,000$ \\
\hline$S_{t}$ & $\mathrm{~mm}$ & Soil tension storage capacity & 0 & 0.00 \\
\hline$b_{g}$ & none & Exponent of recharge function & 1.87 & $1-8$ \\
\hline$q_{c}$ & $\mathrm{~m}^{3} \mathrm{~s}^{-1}$ & Constant flow representing returns/abstractions & 0.2 & $0.00-1$ \\
\hline$\tau_{d}$ & $\mathrm{~h}$ & Time delay & 3.01 & $0.0-8.0$ \\
\hline
\end{tabular}

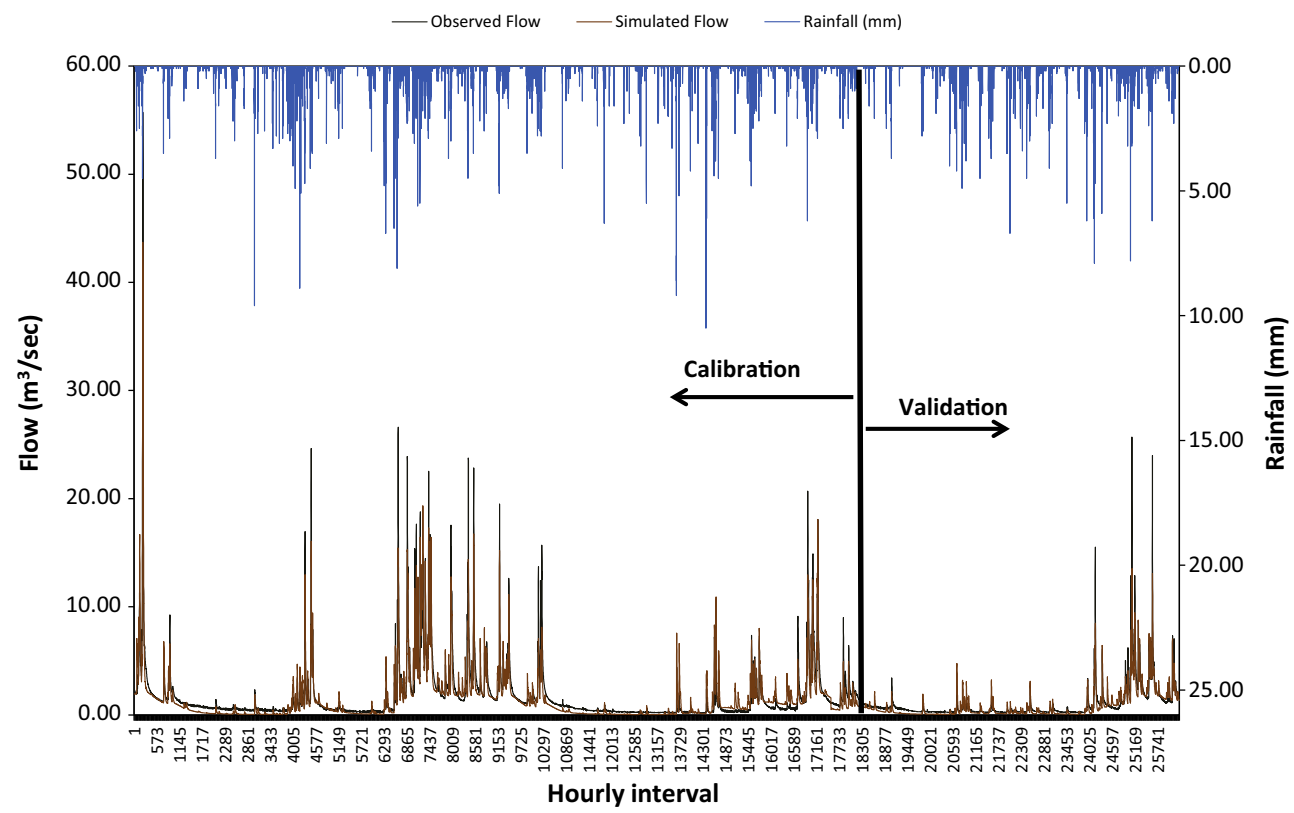

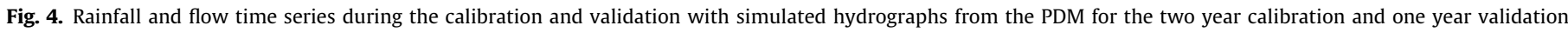
periods. 


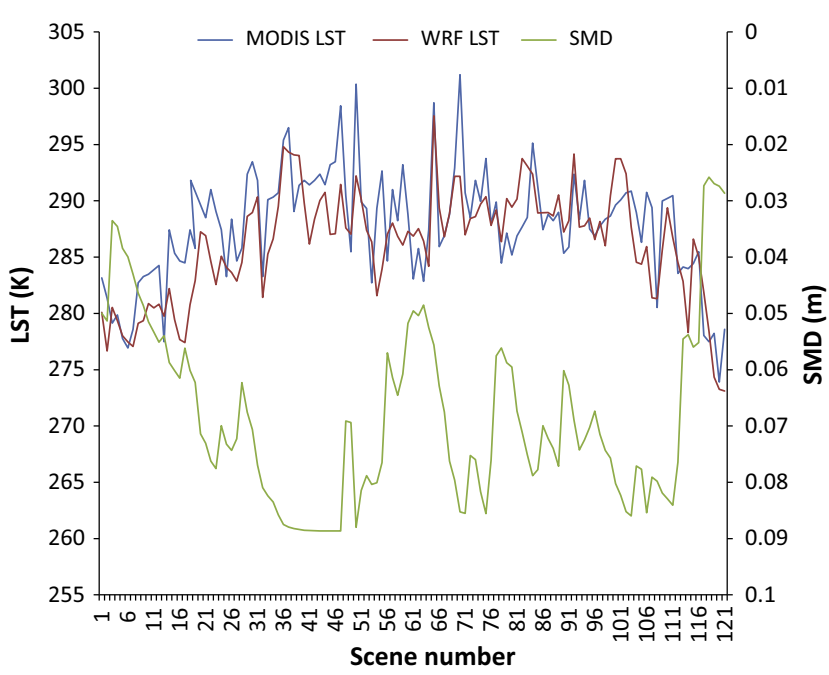

Fig. 5. Graph showing trend of WRF and MODIS LST with PDM SMD variations.

runs, is determined by the values of the correlation $r$ and of the standard deviation (SD) of the modeled data. The closer a label to the reference point is the better the performance of the run is. The tendency to over/under estimate the observed values can also be indicated by the Taylor diagram, generally when the standard deviation of the simulated data is higher than that of the observed values an overestimation can be identified and vice versa.
Table 3

Description of the approaches with roughness parameters ( $h$ and $Q$ ).

\begin{tabular}{clll}
\hline Approaches & Description & $h$ & $Q$ \\
\hline Approach 1 & $\begin{array}{l}\text { SCA-H, Roughness parameter as suggested in } \\
\text { SMOS ATBD, MODIS LST }\end{array}$ & 0.2 & 0 \\
Approach 2 & $\begin{array}{l}\text { SCA-H, Roughness parameter using optimisation } \\
\text { solution, MODIS LST }\end{array}$ & 0.4 & 0.13 \\
Approach 3 & $\begin{array}{l}\text { SCA-H, Roughness parameter as suggested in } \\
\text { SMOS ATBD, WRF LST }\end{array}$ & 0.2 & 0 \\
Approach 4 & $\begin{array}{l}\text { SCA-H, Roughness parameter using optimisation } \\
\text { Solution, WRF LST } \\
\text { SMOS ATBD }\end{array}$ & 0.45 & 0.15 \\
SMOS Level & 0.2 & 0 \\
2 & & &
\end{tabular}

\section{Results and discussion}

\subsection{Soil Moisture Deficit estimation from PDM model}

For the calibration of the PDM model, as mentioned in the methodology, two years of data (February 1, 2009 to January 31, 2011) are used, while for the validation data of one year (February 1,2011 to January 31,2012 ) is taken into account. The optimal separation of slow and fast runoff components are taken into account for PDM calibration (the slow component refers to ground water recharge from soil water drainage routed through subsurface storage while the fast component belongs to direct runoff) along with the estimation of storage time constants (Srivastava et al., 2012a,c). The PDM parameters used in this study for initialization are indicated in Table 2 with the ranges used and the optimal values. The model was validated by simulating one year continuous time
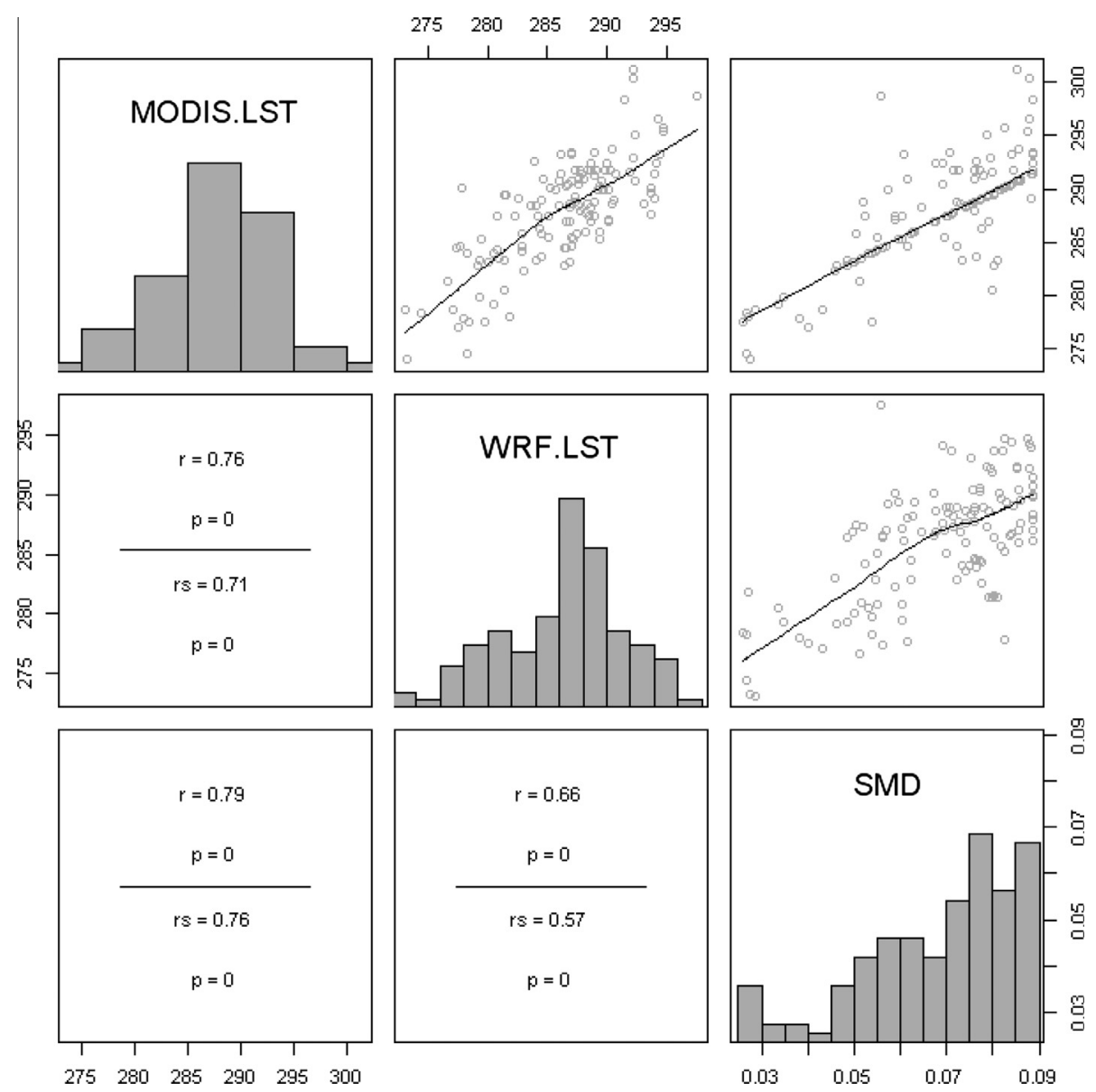

Fig. 6. Correlation matrix plots between MODIS LST, WRF LST and SMD. 


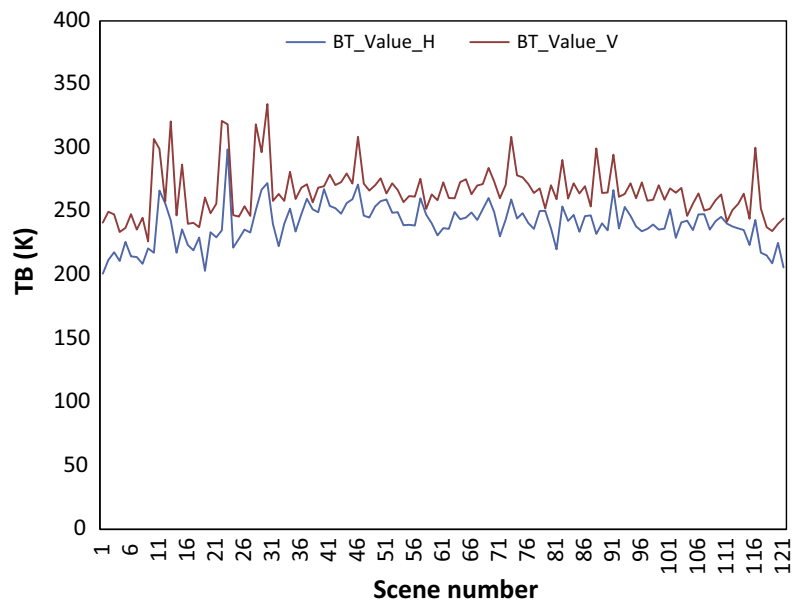

Fig. 7. $H$ and $V$ polarisation brightness temperature over the entire period.

series data. The hydrographs indicate that at some points the model performance can be poor especially on the low-flow portion of the hydrograph where the model is unable to adequately represent the nonlinear processes evident in the recession curves and low flows. However during most of the monitoring period the
PDM model performance is relatively good. The time series between rainfall and flow during the calibration and validation period are shown in Fig. 4. The overall analysis indicates a NSE value of 0.84 during the calibration and 0.81 for the validation. The relevant important variable used in this model is the SMD estimated after calibration and validation of the PDM model. SMD from PDM is used as validation given the fact that the PDM is able to simulate the hydrological processes in the catchment and although the model is calibrated using flow, SMD is an important component of the PDM model. Therefore, SMD is not directly measured, but it can be reliably estimated using the PDM model. This SMD is used to distribute rain to the various types of runoff. If the SMD is low then a sizeable portion of runoff will occur as fast runoff and the remainder to slow base flow as groundwater runoff (Moore, 2007).

In similar studies, the sensitivity analysis and uncertainty estimation of the PDM model for Brue catchment is discussed briefly by Srivastava et al. (2013e). In this analysis, the cumulative distribution estimated for every time step is used to derive the prediction limits for the discharge. The result of a wider confidence boundary suggests that the parameter values are associated with equally good performances and are distributed widely over the parameter space (Yang et al., 2008), whereas the narrow boundary limits show that the best performing parameters are concentrated $\begin{array}{lll}0.1 & 0.3 & 0.5\end{array}$
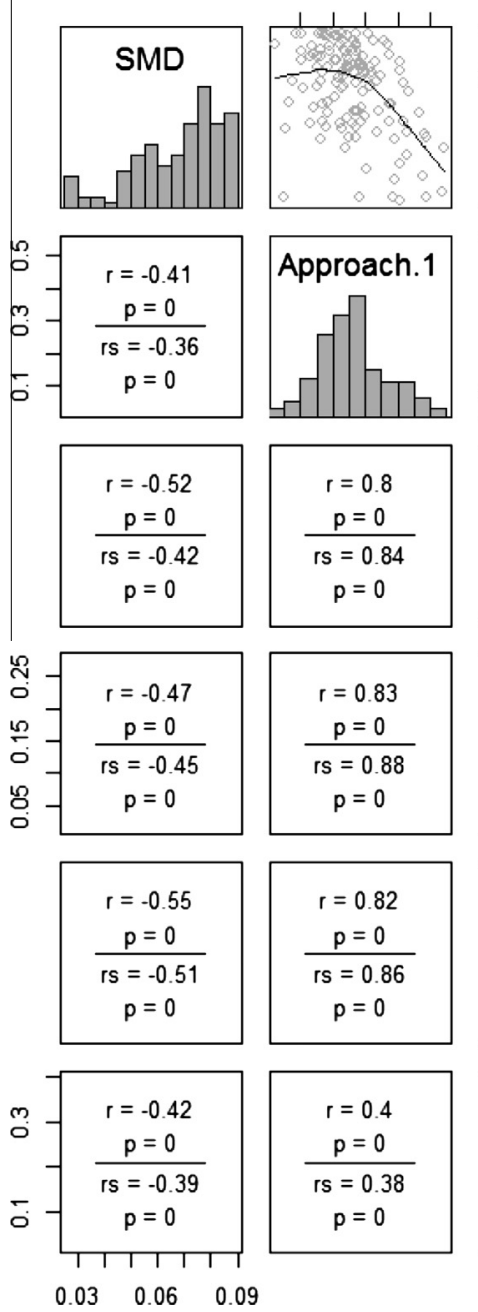

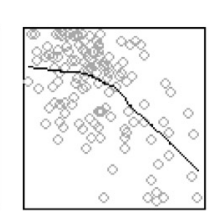

$0.05 \quad 0.15 \quad 0.25$
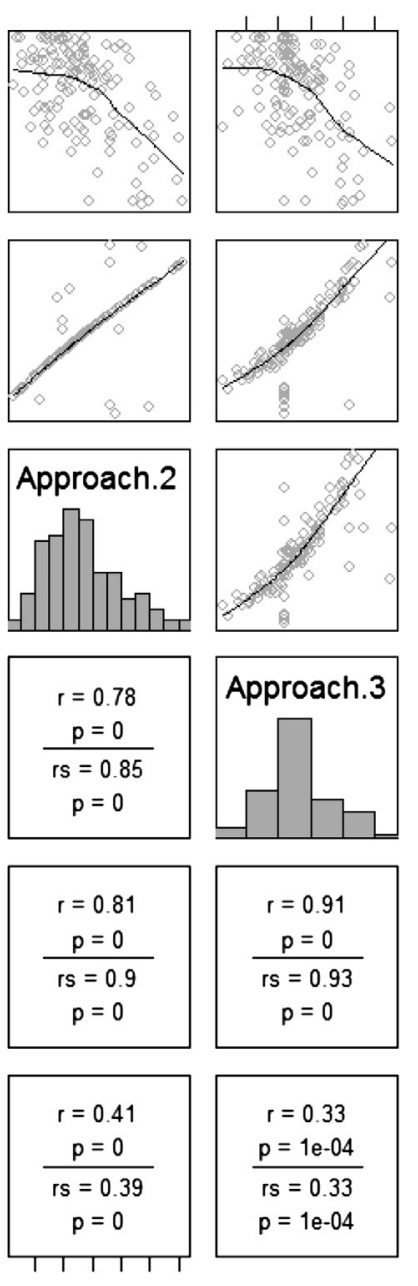

$\begin{array}{lll}0.2 & 0.4 & 0.6\end{array}$
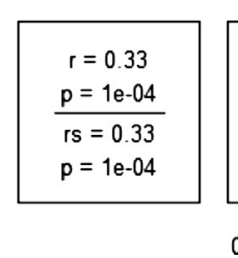

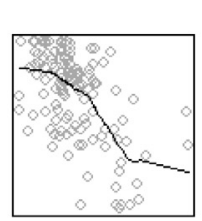

$0.1 \quad 0.3$
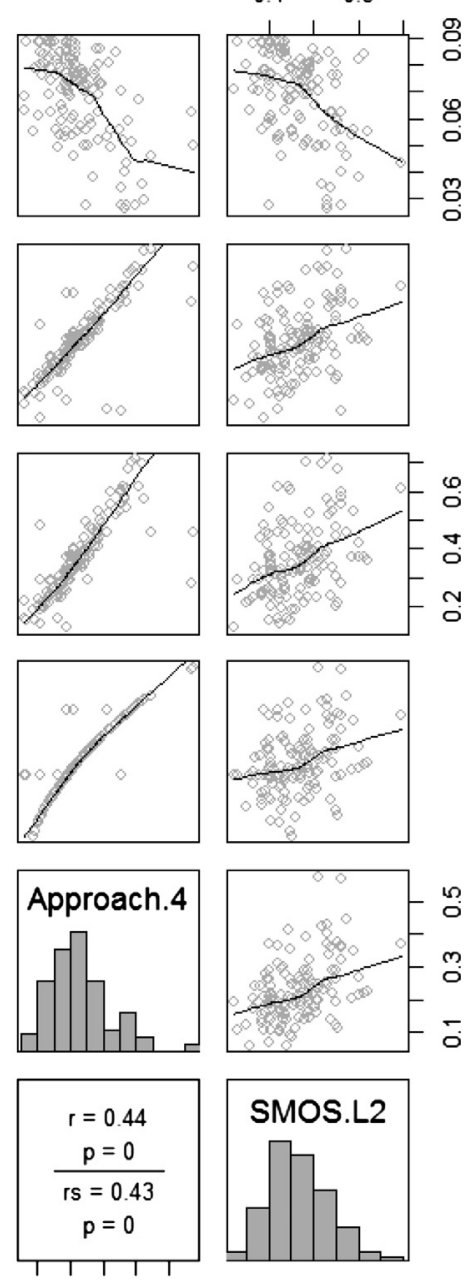

$\begin{array}{lll}0.1 & 0.3 & 0.5\end{array}$
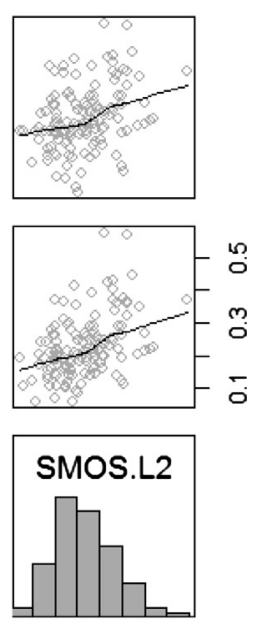

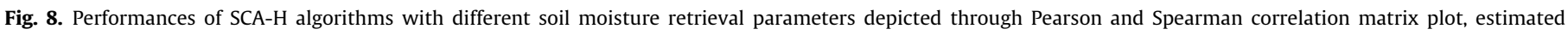
between SMD and retrieved soil moisture. 
Approach 1
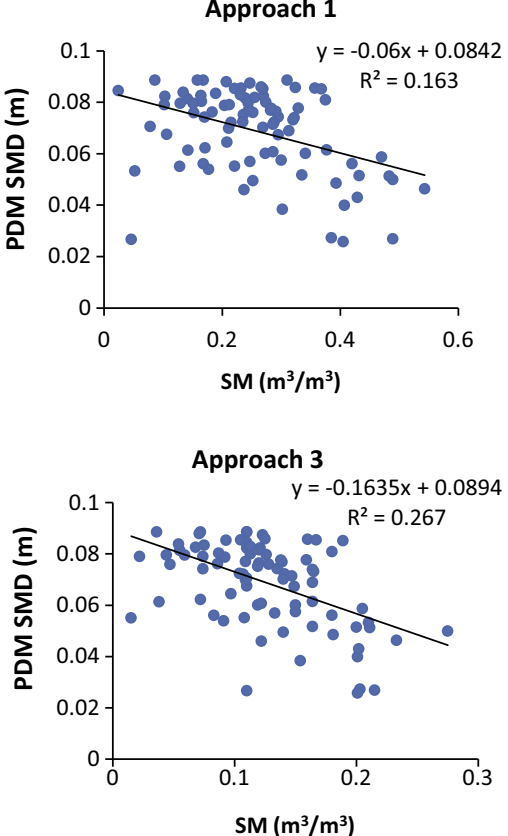

Approach 2

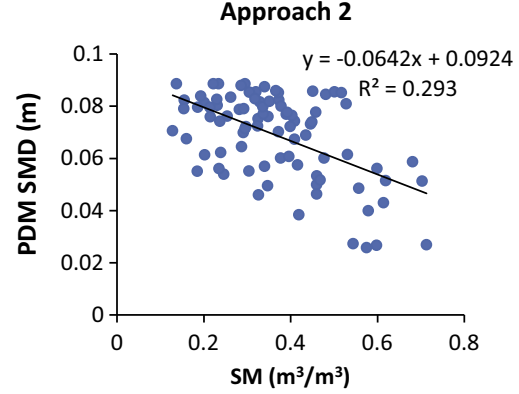

Approach 4

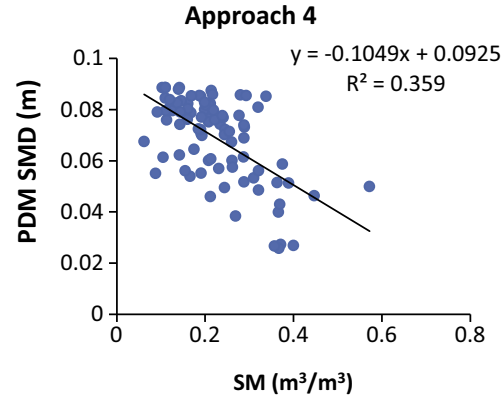

SMOS L2

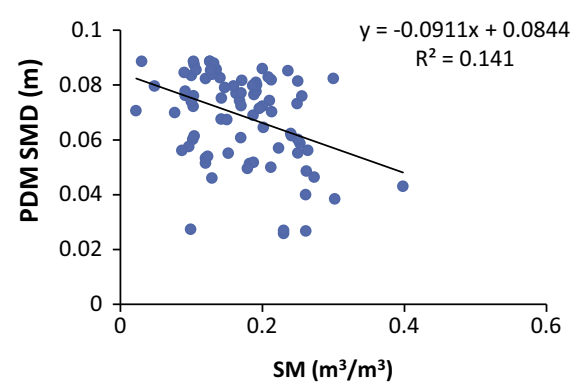

Fig. 9. Calibration plots used for deriving empirical relationships (where SM = Soil moisture).

in a smaller area. The analysis reveals that the PDM model tends to match the observed hydrographs quite well with some lower performance seen in low flow conditions. The goodness of calibration and prediction uncertainty is judged on the basis of the $p$-factor (observations bracketed by the prediction uncertainty) and the $r$-factor (achievement of small uncertainty band). The plot obtained from the 95\% Uncertainty Band (95UB) based on the parameter uncertainty is quite satisfactory ( $r$-factor $=>$ calibration $=0.68$; and validation $=0.65$ ) and parameter uncertainty and uncertainty sources represented by the GLUE model bracketed more than $84 \%$ of the observed points for calibration and $71 \%$ for the validation periods ( $p$-factor), reveals a satisfactory model performance for this catchment (Srivastava et al., 2013d).

\subsection{Soil moisture retrieval parameters}

The main soil moisture retrieval parameters used in this study are land surface temperature (LST), MODIS LAI, roughness parameters ( $h$ and $Q$ ) and vegetation scattering albedo $(\omega)$. In this study the LST is estimated through MODIS and WRF-NOAH LSM downscaled ECWMF datasets and separately used for moisture retrieval performances following the RTE. The MODIS LAI is used for VOD estimation and fixed for all retrieval trials. The roughness parameters are estimated through locally optimising the algorithm (SCA-H) and the default value is also used as given in SMOS ATBD document for low vegetation cover. The default value of 0.05 for vegetation scattering albedo is used. The trend obtained with
SMD, WRF and MODIS LST is shown in Fig. 5. The analysis revealed a similar pattern between both the datasets and gave a similar response with SMD. The result shows that when soil temperature is high, SMD is also greater indicating that both are related to each other. The correlation matrix plot is shown in Fig. 6. The correlation analysis indicates a higher linearity of MODIS LST with SMD while the WRF LST shows possibility of non-linearity with the SMD because of existing differences between the Pearson and Spearman's correlation. In previous studies many authors have shown that at low frequencies when surface roughness condition is unknown, a value of zero is often assigned to the $Q$ parameter and for low vegetation it is recommended to use the value of $\sim 0.05$ for $Q$ and $\sim 0.2$ for $h$ which are suitable for most of the conditions (Jackson, 1993; Wang et al., 2009). However, after optimization using the Levenberg-Marquardt (LM) algorithm the range of $h$ is found to be between $0.1-0.4$ and for $Q$ it is between 0.03 and 0.15 with different input parameter conditions.

The LAI is estimated from the MOD15 product available on 8 days basis. Here we assumed that the LAI is persistent for 8 days because of very low vegetation activities, hence the LAI forcing for soil moisture retrieval is changed in the algorithms every 8 days. The LAI is used for the VOD estimation by means of simple empirical relations as suggested by Jackson and Schmugge (1991) and Wigneron et al. (2002). Here in this study, the LAI is firstly converted to VWC using the relationship as mentioned in (Wigneron et al., 2002) and then VWC is converted to $\tau$ using the constant as suggested for low vegetation by Jackson and Schmugge 

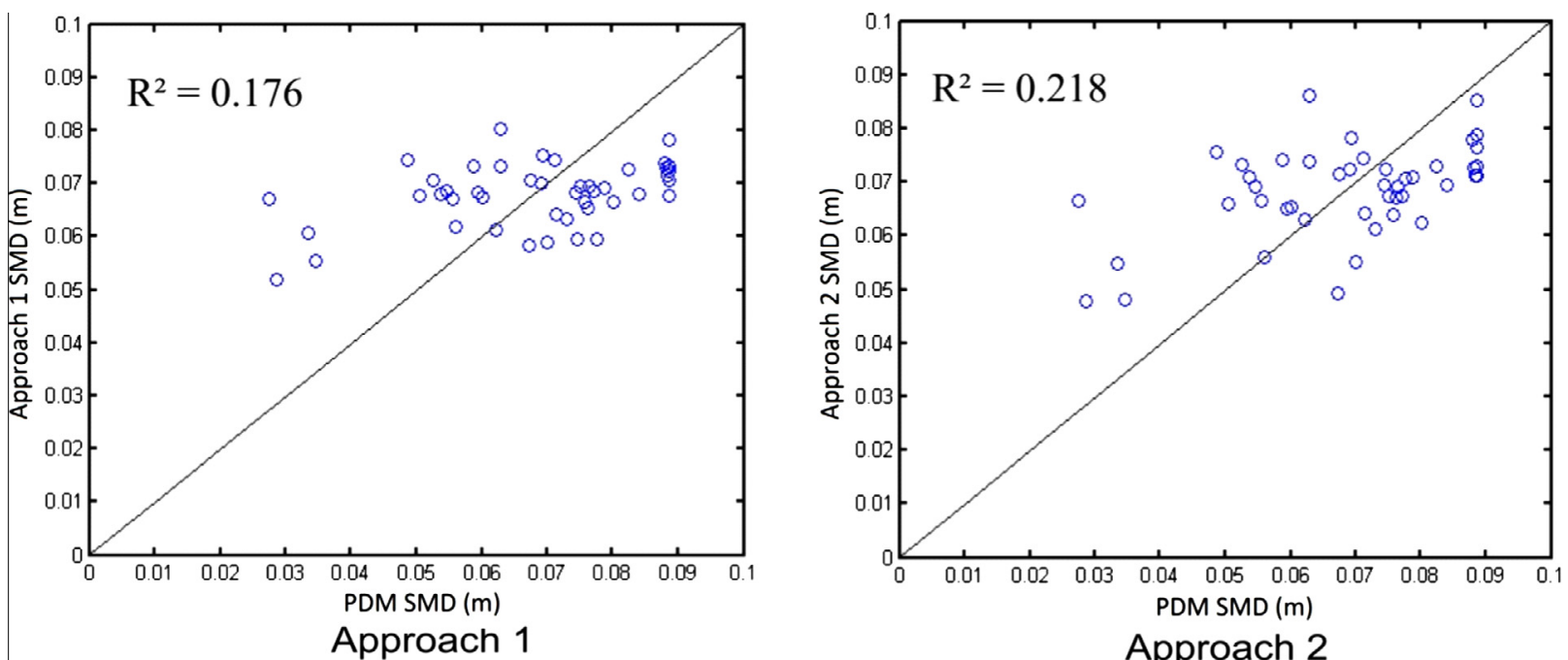

Approach 2

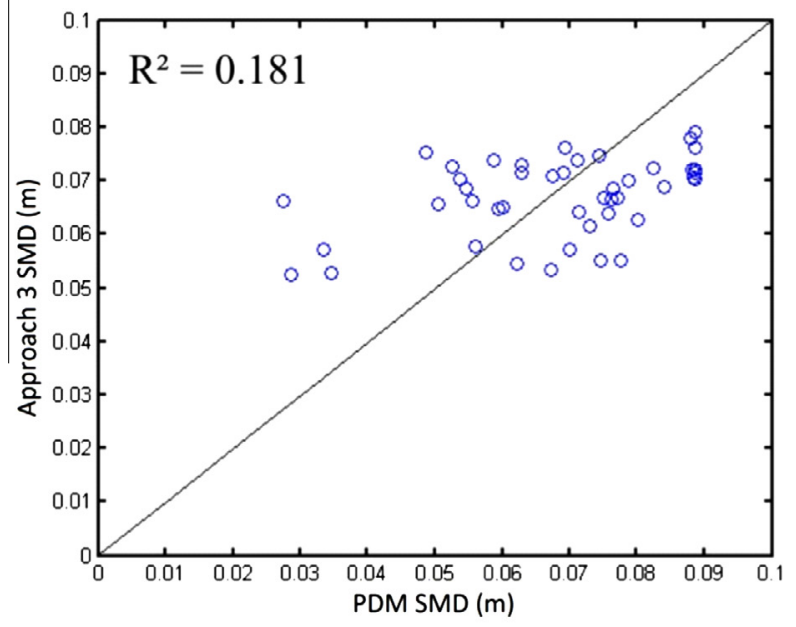

Approach 3

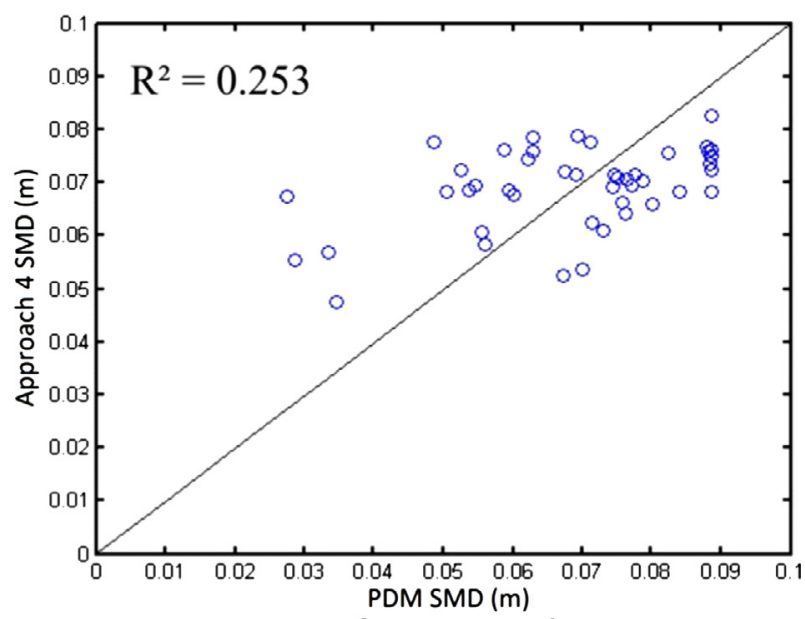

Approacn 4

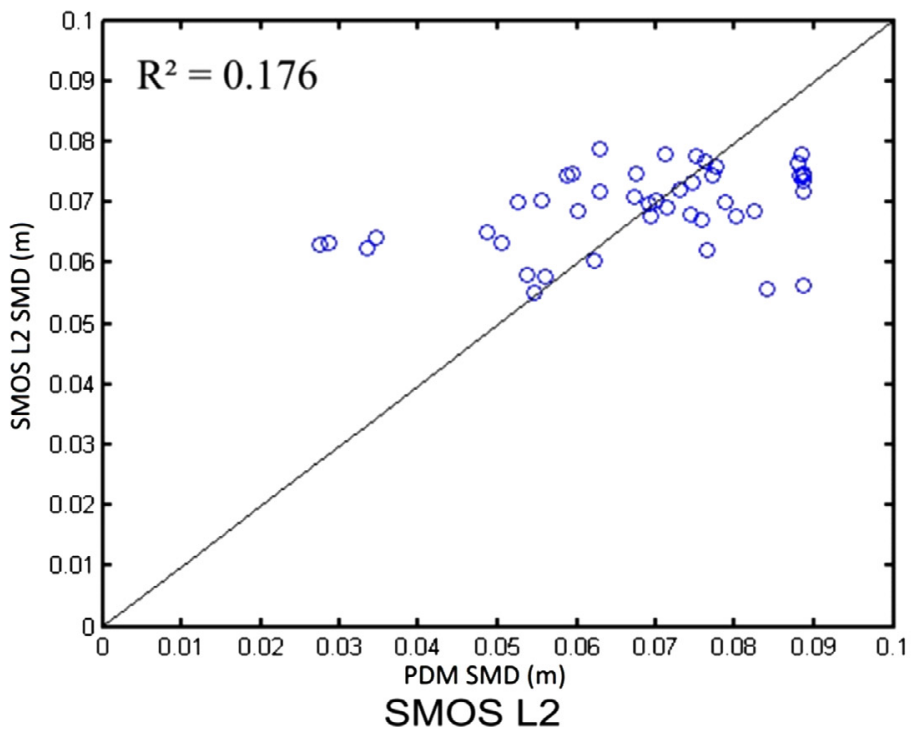

Fig. 10. Validations plots for the approaches and SMOS level 2 with SMD.

(1991), discussed in Section 2.4. It should be pointed out that there is a mismatch between the study catchment and SMOS pixels. Ideally, it would be great if SMOS pixels and the study catchment area are of the same size. However, this mismatch of catchment sizes and hydrological measurements are expected in practice as catchments always have irregular shapes sometime bigger and sometime smaller than a SMOS pixel. In practice, the mismatch can be minimized using regression fitting models as long as SMOS 
derived SMD is able to provide useful soil moisture information for hydrological modeling. The different approaches used in this study are summarized in Table 3 along with the values of roughness parameter used and small description of the approaches.

\subsection{Performances of the algorithms}

The brightness temperature (TB) retrieved for SMOS Level 1C scenes over Brue are shown in Fig. 7 with respect to $H$ and $V$ channels. The TB result indicates that in most of the cases $H$ and $V$ polarisations are following the criteria $\mathrm{TB}<340 \mathrm{~K}$ and MPDI $>0.0$ which indicates that the selected brightness temperature is of reasonable quality to use in this study. The results are presented for single channel using $H$ and $V$ polarisations. The scatter plots of input data are presented to identify how the changes in the soil moisture retrieval parameters influence the algorithm performance. From the data analysis, it can be revealed that the results are sensitive to the selection of the $h$ and $Q$ parameters. By using the optimized $h$ and $Q$ datasets the results are highly improved as compared with the global values as given in SMOS ATBD document (Kerr et al., 2006).

The scatter plots representing the performances of different approaches in terms of correlations are shown in Fig. 8. The notable things observed in this work are the some lower performance of SMOS L2 with SMD. It could be possible as SMOS L2 is based on global default parameters which are not true everywhere, in case more accurate input parameters are available from local conditions, performance should be improved. All the plots indicate an inverse relation with the SMOS SMD; hence a negative correlation is expected between the estimated soil moisture and SMD. The best correlation statistics are given by the $H$ polarization approaches such as approach $4(r=-0.55)$ followed by approach $2(r=-0.52)$, approach $3(r=-0.47)$ and approach $1(r=-0.41)$. The SMOS L2 correlation performance is similar to approach 1 which indicates the LST conditions used in SMOS ATBD are similar to MODIS measurements. It may be noted that some pixels with a high amount flooding conditions can be attributed to the seasonal behavior of large rivers or large rain events causing significant ponding (Kerr et al., 2012). Another source of error can be linked to water bodies. The dynamics of water bodies is very unpredictable because of seasonal variations, floods or freezing.

\subsection{Soil Moisture Deficit estimation using empirical relationships}

The scatter plots for the datasets are depicted in Fig. 10 along with the estimated Pearson and Spearman correlations. The two correlation statistics are calculated to make sure the linear and nonlinear choices for the model development. The Spearman $\left(r_{\text {spearman }}\right)$ and Pearson $\left(r_{\text {pearson }}\right)$ correlation statistics between SMOS soil moisture which yields nearly similar values, indicate that there is no strong nonlinearity existed and linear curve fitting could be a useful choice because of its simplicity (Blumer et al., 1987). The linear model estimated using the PDM SMD and soil moisture from various algorithms during the calibration are used for developing an empirical relationship using linear regression model. For deriving the relationship, the calibration and validation datasets are first divided into two lots. From each month, two thirds of the data are taken as calibration and the other third as validation, so that both calibration and validation data are representative of all the seasons. The results of only SCA-H approaches are presented through scatter plots, however in Taylor plot all the performances are reported estimated during the validation. The linear curve fitting used for calculation of the empirical relationships are shown in Fig. 9, while the validation results obtained by applying the linear curve fitting equations are presented through Fig. 10. The square of correlation during the calibration indicates a value of $R^{2}=0.359$ for approach 4 followed by the approach $2\left(R^{2}=0.293\right)$, approach 3

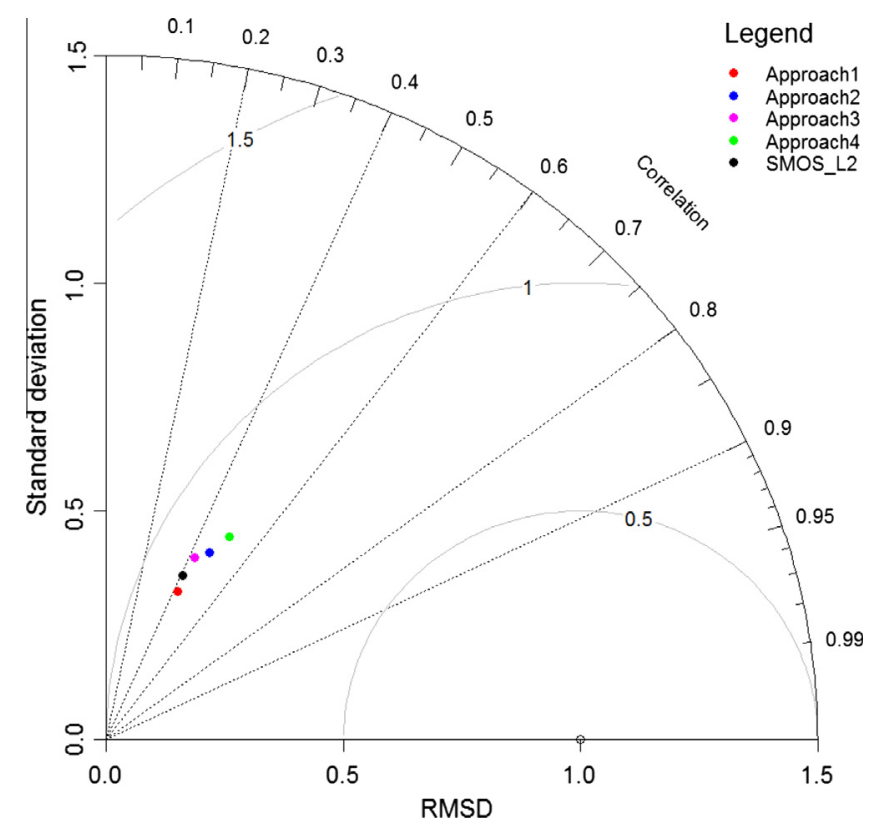

Fig. 11. Taylor plots for performance measurement during validation.

$\left(R^{2}=0.267\right)$ and approach $1\left(R^{2}=0.163\right)$. Similarly, during the validation a higher performance is reported by approach 4 and a comparable trend is obtained like calibration with other SCA $\mathrm{H}$ approaches. The higher performance of approach 4 can be attributed to a low impact of roughness on $H$ polarisation and also to an accurate estimation of LST using the WRF-NOAH LSM which is further supplemented by the optimised solutions of $h$ and $Q$.

The Taylor plot (Fig. 11) is used here to show the ability of the performance of all the approaches used in this study in comparison to the PDM SMD during the validation. The circle mark in the $x$-axis in the Taylor plot, called the reference point, closer to this point represents the perfect fit between algorithm results and data. The tendency to over/under estimate the PDM SMD is also indicated by the Taylor diagram, generally when the standard deviation of the simulated SMD is higher than that of the observed values an overestimation can be predicted and reverse is the case for underestimation. The Taylor plot shows that in validation a higher performance of approach 4 is reported. The statistics obtained are evident for a better performance in the case of WRF LST and optimised solution for roughness parameters. It shows that the SCA-H algorithm with WRF LST and roughness modification has a higher performance than the SMOS level 2 products for SMD estimation and could be a suitable choice for soil moisture retrieval for hydrological applications. The higher performance of WRF LST can be attributed to more accurate representation of surface temperature (similar to SMOS overpass time) and because of sophisticated numerical parameterization schemes. Close vicinity of the approaches using MODIS optimized solution is also seen with slight underestimation. In spite of the mismatch between SMOS and hydrological SMD in space $(\sim 40 \mathrm{~km}$ grid vs. about $\sim 12 \mathrm{~km}$ grid) and with depth (land surface vs. deep soil layer), the approaches mentioned above have justifiable performances because the SMOS data are transformed by the regression models through the correlation between the SMOS retrieved soil moisture and hydrological SMD.

\section{Conclusions}

In-situ observations of soil moisture are currently restricted to specific locations, and such measurements do not represent the spatial variation over a large area and are therefore insufficient 
for regional and global studies. The promising solution for large scale soil moisture measurements is satellite based approaches such as microwave using low frequency (L band radiometers). The essential soil moisture retrieval parameters are soil roughness, LST and VOD. The efficient estimation of these parameters is found to be very important for improved soil moisture retrieval for SMD estimation. However these parameters are difficult to obtain because of their highly variable nature. The soil moisture retrieval parameters such as LST and VOD can be simulated using MODIS or mesoscale model based products. As a mesocscale model the WRFNOAH LSM is used in this study which can provide the dynamic datasets for soil moisture retrieval. The initial evaluation of SMOS L2 using the correlation statistics between SMOS soil moisture and PDM SMD indicates that SCA H gives a better performance than the original SMOS L2 product using WRF-NOAH LSM downscaled datasets. The high performance of WRF-NOAH LSM downscaled LST could be attributed to its nearly same temporal resolution as compared to SMOS overpass than MODIS. All the algorithms produce better results with locally calibrated roughness parameters because they represent the conditions more accurately as compared with the default global values. However, these locally calibrated methods are not sufficient everywhere and hence a more accurate method for global use is required which could be possible through regionalization approaches (Han and Jaafar, 2013).

In comparison between all the available datasets, it is worthwhile to mention that the MODIS data require least calculations for estimation of soil moisture retrieval parameters as compared to WRF-NOAH LSM downscaling which require a more rigorous calculations and expertise. Further the estimation of the datasets from WRF-NOAH LSM is computationally more expensive than MODIS. There is still room in which the microwave remote sensing of soil moisture can be improved. One factor is vegetation scattering albedo. The soil moisture retrieval complexity increases when the soil is covered by vegetation, as emissivity is severely attenuated by the height of the canopy layer: it absorbs and scatters the radiation emanating from the soil and also adds its own contribution. The solution such as inclusion of first order vegetation scattering solution for albedo could be promising for efficient soil moisture retrieval. The other challenges of retrieval or inversion techniques are to reconstruct the environmental parameters from the measured signal by using a minimum of auxiliary data. The more research in the technical literature domain is required for the auxiliary data generation. The current formulation used in study is only suited for zero order solution. Future research will focus on estimating soil moisture using the first order solution and improvement of auxiliary datasets.

This study provides hydrologists with valuable information on roughness parameter estimation, WRF model uses and its applicability for soil moisture retrieval, in agreement to hydrological model based product. However, further exploration of this potentially valuable data source by the hydro-meteorological community is recommended so that useful experience and knowledge could be accumulated in the technical literature domain for other geographical locations and climatic conditions.

\section{Acknowledgment}

The first author would like to thank the Commonwealth Scholarship Commission, British Council, United Kingdom and Ministry of Human Resource Development, Government of India for providing the necessary support and funding for this research. The authors are highly thankful to the European Space Agency for providing the SMOS data especially to Dr. Susanne Mecklenburg. The authors would like to acknowledge the British Atmospheric Data Centre and Environment Agency, United Kingdom for providing the ground observation datasets. The first author would like to thanks the SMOS team especially Yann Kerr and Philippe Richaume for giving useful information and training over SMOS at CESBIO, Toulouse, France and providing an insight to the retrieval algorithms. The authors also acknowledge the Advanced Computing Research Centre at the University of Bristol for providing the access to supercomputer facility (The Blue Crystal).

\section{References}

Aubert, D., Loumagne, C., Oudin, L., 2003. Sequential assimilation of soil moisture and streamflow data in a conceptual rainfall-runoff model. J. Hydrol. 280 (1), $145-161$.

Bell, V., Moore, R., 1998. A grid-based distributed flood forecasting model for use with weather radar data: Part 2. Case studies. Hydrol. Earth Syst. Sci. 2 (2/3) 283-298.

Beven, K., Binley, A., 2006. The future of distributed models: model calibration and uncertainty prediction. Hydrol. Process. 6 (3), 279-298.

Beven, K., Wood, E.F., 1983. Catchment geomorphology and the dynamics of runoff contributing areas. J. Hydrol. 65 (1), 139-158.

Black, T.L., 1994. The new NMC mesoscale Eta model: description and forecast examples. Weather Forecast 9 (2), 265-278.

Blasone, R.-S., Madsen, H., Rosbjerg, D., 2008. Uncertainty assessment of integrated distributed hydrological models using GLUE with Markov chain Monte Carlo sampling. J. Hydrol. 353 (1), 18-32.

Blumer, A., Ehrenfeucht, A., Haussler, D., Warmuth, M.K., 1987. Occam’s razor. Inf. Process. Lett. 24 (6), 377-380.

Chen, F., Mitchell, K., Schaake, J., Xue, Y., Pan, H.-L., Koren, V., Duan, Q., Ek, M., Betts, A., 1996. Modeling of land surface evaporation by four schemes and comparison with FIFE observations. J. Geophys. Res-Atmos. (1984-2012) 101 (D3), 7251 7268 .

Chen, F., Dudhia, J., 2001. Coupling an advanced land surface-hydrology model with the Penn State-NCAR MM5 modeling system. Part I: Model implementation and sensitivity. Mon. Weather Rev. 129 (4), 569-585.

Cramer, W. et al., 2001. Global response of terrestrial ecosystem structure and function to $\mathrm{CO} 2$ and climate change: results from six dynamic global vegetation models. Glob. Change Biol. 7 (4), 357-373.

Croke, B.F., Jakeman, A.J., 2004. A catchment moisture deficit module for the IHACRES rainfall-runoff model. Environ. Model. Softw. 19 (1), 1-5.

de Jeu, R.A., Holmes, T.R., Parinussa, R.M., Owe, M., 2014. A spatially coherent global soil moisture product with improved temporal resolution. J. Hydrol. 516 284-296.

Dudhia, J., 1989. Numerical study of convection observed during the winter monsoon experiment using a mesoscale two-dimensional model. J. Atmos. Sci. 46 (20), 3077-3107.

Engman, E.T., 1990. Progress in microwave remote sensing of soil moisture. Can. J Remote Sens. 16 (3), 6-14.

Entekhabi, D. et al., 2010. The soil moisture active passive (SMAP) mission. Proc IEEE 98 (5), 704-716.

Evans, J., Jakeman, A., 1998. Development of a simple, catchment-scale, rainfallevapotranspiration-runoff model. Environ. Model. Softw. 13 (3), 385-393.

Goward, S.N., Xue, Y., Czajkowski, K.P., 2002. Evaluating land surface moisture conditions from the remotely sensed temperature/vegetation index measurements: an exploration with the simplified simple biosphere model. Remote Sens. Environ. 79 (2), 225-242.

Han, D., Bray, M., 2006. Automated Thiessen polygon generation. Water Resour. Res. $42(11)$.

Han, D., Jaafar, W.Z.W., 2013. Model structure exploration for index flood regionalization. Hydrol. Process. 27 (20), 2903-2917.

Heikkilä, U., Sandvik, A., Sorteberg, A., 2011. Dynamical downscaling of ERA-40 in complex terrain using the WRF regional climate model. Clim. Dyn. 37 (7-8), $1551-1564$.

Hu, X.M., Nielsen-Gammon, J.W., Zhang, F., 2010. Evaluation of three planetary boundary layer schemes in the WRF model. J. Appl. Meteorol. Climatol. 49 (9) $1831-1844$.

Islam, T., Srivastava, P.K., Gupta, M., Zhu, X., Mukherjee, S., 2014. Computational Intelligence Techniques in Earth and Environmental Sciences. Springer, Netherlands, ISBN 978-94-017-8642-3.

Jackson, T., Schmugge, T., 1991. Vegetation effects on the microwave emission of soils. Remote Sens. Environ. 36 (3), 203-212.

Jackson, T.J., 1993. III. Measuring surface soil moisture using passive microwave remote sensing. Hydrol. Process. 7 (2), 139-152.

Jackson, T.J., Hsu, A.Y., O'Neill, P.E., 2002. Surface soil moisture retrieval and mapping using high-frequency microwave satellite observations in the Southern Great Plains. J. Hydrometeorol. 3 (6), 688-699.

Jackson, T.J., O'Neill, P.E., Swift, C.T., 1997. Passive microwave observation of diurnal surface soil moisture. Geosci. Remote Sens., IEEE Trans. 35 (5), 1210-1222.

Jacquemin, B., Noilhan, J., 1990. Sensitivity study and validation of a land surface parameterization using the HAPEX-MOBILHY data set. Bound.-Layer Meteorol. 52 (1), 93-134.

Jin, X., Xu, C.-Y., Zhang, Q., Singh, V., 2010. Parameter and modeling uncertainty simulated by GLUE and a formal Bayesian method for a conceptual hydrological model. J. Hydrol. 383 (3), 147-155. 
Kerr, Y. et al., 2006. SMOS level 2 processor soil moisture algorithm theoretical basis document (ATBD). SM-ESL (CBSA), CESBIO, Toulouse, SO-TN-ESL-SM-GS-0001, V5. a, 15/03

Kerr, Y.H. et al., 2012. The SMOS soil moisture retrieval algorithm. Geosci. Remote Sens., IEEE Trans. 50 (5), 1384-1403.

Kerr, Y.H. et al., 2001. Soil moisture retrieval from space: the Soil Moisture and Ocean Salinity (SMOS) mission. Geosci. Remote Sens., IEEE Trans. 39 (8), 17291735.

Krause, P., Boyle, D.P., Bäse, F., 2005. Comparison of different efficiency criteria for hydrological model assessment. Adv. Geosci. 5 (5), 89-97.

Laymon, C.A., Manu, A., Crosson, W.L., Jackson, T.J., 1999. Defining the range of uncertainty associated with remotely sensed soil moisture estimates with microwave radiometers. Remote Sens. Int. Soc. Optics Photonic., 504-512.

Liu, J., Han, D., 2013. On selection of the optimal data time interval for real-time hydrological forecasting. Hydrol. Earth Syst. Sci. 17 (9), 3639-3659.

Liu, Y. et al., 2012. Trend-preserving blending of passive and active microwave soil moisture retrievals. Remote Sens. Environ. 123, 280-297.

Lo, J.C.F., Yang, Z.L., Pielke, R.A., 2008. Assessment of three dynamical climate downscaling methods using the Weather Research and Forecasting (WRF) model. J. Geophys. Res.: Atmos. (1984-2012), 113(D9).

Mahfouf, J.-F., 1991. Analysis of soil moisture from near-surface parameters: a feasibility study. J. Appl. Meteorol. 30 (11), 1534-1547.

McCuen, R.H., Knight, Z., Cutter, A.G., 2006. Evaluation of the Nash-Sutcliffe efficiency index. J. Hydrol. Eng. 11 (6), 597-602.

Merz, B., Plate, E.J., 1997. An analysis of the effects of spatial variability of soil and soil moisture on runoff. Water Resour. Res. 33 (12), 2909-2922.

Mladenova, I. et al., 2014. Remote monitoring of soil moisture using passive microwave-based techniques-theoretical basis and overview of selected algorithms for AMSR-E. Remote Sens. Environ. 144, 197-213.

Mlawer, E.J., Taubman, S.J., Brown, P.D., Iacono, M.J., Clough, S.A., 1997. Radiative transfer for inhomogeneous atmospheres: RRTM, a validated correlated-k model for the longwave. J. Geophys. Res. 102 (D14), 16663-16682.

Mo, T., Choudhury, B., Schmugge, T., Wang, J., Jackson, T., 1982. A model for microwave emission from vegetation-covered fields. J. Geophys. Res.: Oceans 87 (C13), 11229-11237 (1978-2012).

Moore, R., 2007. The PDM rainfall-runoff model. Hydrol. Earth Syst. Sci. 11 (1), $483-$ 499.

Nash, J.E., Sutcliffe, J., 1970. River flow forecasting through conceptual models part I-A discussion of principles. J. Hydrol. 10 (3), 282-290.

Owe, M., de Jeu, R., Walker, J., 2001. A methodology for surface soil moisture and vegetation optical depth retrieval using the microwave polarization difference index. Geosci. Remote Sens., IEEE Trans. 39 (8), 1643-1654.

Pan, H.-L., Mahrt, L., 1987. Interaction between soil hydrology and boundary-layer development. Bound-Lay. Meteorol. 38 (1), 185-202.

Pinori, S., Crapolicchio, R., Mecklenburg, S., 2008. Preparing the ESA-SMOS (soil moisture and ocean salinity) mission-overview of the user data products and data distribution strategy. Microwave Radiometry and Remote Sensing of the Environment. MICRORAD 2008. IEEE, pp. 1-4.

Powers, J.G., 2007. Numerical prediction of an Antarctic severe wind event with the Weather Research and Forecasting (WRF) model. Mon. Weather Rev. 135 (9), 3134-3157.

Routray, A., Mohanty, U., Niyogi, D., Rizvi, S.R.H., Osuri, K.K., 2010. Simulation of heavy rainfall events over Indian monsoon region using WRF-3DVAR data assimilation system. Meteorol. Atmos. Phys. 106 (1), 107-125.

Sánchez-Ruiz, S. et al., 2014. Combining SMOS with visible and near/shortwave/ thermal infrared satellite data for high resolution soil moisture estimates. J. Hydrol. 516, 273-283.

Sandholt, I., Rasmussen, K., Andersen, J., 2002. A simple interpretation of the surface temperature/vegetation index space for assessment of surface moisture status. Remote Sens. Environ. 79 (2), 213-224.

Schaake, J.C., Koren, V.I. Duan, QY. Mitchell, K. Chen, F. 1996. Simple wate balance model for estimating runoff at different spatial and temporal scales. J. Geophys. Res. D: Atmos. 101, 7461-7475.

Schmugge, T., O’Neill, P.E., Wang, J.R., 1986. Passive microwave soil moisture research. Geosci. Remote Sens. IEEE Trans. 1, 12-22.
Schwartz, C.S. et al., 2009. Next-day convection-allowing WRF model guidance: a second look at 2-km versus 4-km grid spacing. Mon. Weather Rev. 137 (10), 3351-3372.

Scott, C.A., Bastiaanssen, W.G.M., 2003. Mapping root zone soil moisture using remotely sensed optical imagery. J. Irrig. Drain. Eng. 129, 326.

Srivastava, P.K., 2013. Soil Moisture Estimation from SMOS Satellite and Mesoscale Model for Hydrological Applications. PhD Thesis, University of Bristol, Bristol, United Kingdom.

Srivastava, P.K., Han, D., Ramirez, M.R., Islam, T., 2013a. Machine learning techniques for downscaling SMOS Satellite Soil Moisture Using MODIS land surface temperature for hydrological application. Water Resour. Manage 27 (8), 3127-3144.

Srivastava, P.K., Han, D., Rico-Ramirez, M., Al-Shrafany, D., Islam, T., 2013b. Data fusion techniques for improving soil moisture deficit using SMOS satellite and WRF-NOAH Land Surface Model. Water Resour. Manage 27 (15), 5069-5087.

Srivastava, P.K., Han, D., Rico-Ramirez, M.A., 2012a. Assessment of SMOS satellite derived soil moisture for soil moisture deficit stimation. In: Prediction in Ungauged Basin (PUBS) Symposium. Delft University of Technology, Delft, Netherlands and IAHS, 22-25 October 2012.

Srivastava, P.K., Han, D., Rico-Ramirez, M.A., Bray, M., Islam, T., 2012b. Selection of classification techniques for land use/land cover change investigation. Adv. Space Res. 50 (9), 1250-1265.

Srivastava, P.K., Han, D., Rico Ramirez, M.A., Islam, T., 2013c. Appraisal of SMOS soil moisture at a catchment scale in a temperate maritime climate. J. Hydrol. 498, 292-304.

Srivastava, PK, Han, D, Rico Ramirez, M.A Islam, T, 2013d Comparative assessment of evapotranspiration derived from NCEP and ECMWF global datasets through Weather Research and Forecasting model. Atmos. Sci. Lett. 14 (2), 118-125.

Srivastava, P.K., Han, D., Rico Ramirez, M.A., Islam, T., 2013e. Sensitivity and uncertainty analysis of mesoscale model downscaled hydro-meteorological variables for discharge prediction. Hydrol. Process. http://dx.doi.org/10.1002/ hyp.9946.

Su, Z. et al., 2011. The Tibetan Plateau observatory of plateau scale soil moisture and soil temperature (Tibet-Obs) for quantifying uncertainties in coarse resolution satellite and model products. Hydrol. Earth Syst. Sci. 15 (7), 2303-2316.

Taylor, K.E., 2001. Summarizing multiple aspects of model performance in a single diagram. J. Geophys. Res 106 (D7), 7183-7192.

Thakur, J., Srivastava, P.K., Singh, S.K., 2012. Ecological monitoring of wetlands in semi-arid region of Konya closed Basin, Turkey. Reg. Environ. Change 12 (1), 133-144.

Wang, L., Qu, J.J., 2009. Satellite remote sensing applications for surface soil moisture monitoring: a review. Front Earth Sci. China 3 (2), 237-247.

Wang, L. et al., 2009. Surface soil moisture estimates from AMSR-E observations over an arid area, Northwest China. Hydrol. Earth Syst. Sci. Discuss. 6 (1).

Wigneron, J.-P., Calvet, J.-C., De Rosnay, P., Kerr, Y.H., 2006. L-MEB: A simple model at L-band for the continental areas-Application to the simulation of a halfdegree resolution and global scale data set. <http://hal.archives-ouvertes.fr/ird$00423064 />$

Wigneron, J.-P., Chanzy, A., Calvet, J.-C., Olioso, A., Kerr, Y., 2002. Modeling approaches to assimilating $\mathrm{L}$ band passive microwave observations over land surfaces. J. Geophys. Res. 107 (D14), 4219.

Wigneron, J.-P. et al., 2007. L-band Microwave Emission of the Biosphere (L-MEB) Model: description and calibration against experimental data sets over crop fields. Remote Sens. Environ. 107 (4), 639-655.

Yang, J., Reichert, P., Abbaspour, K., Xia, J., Yang, H., 2008. Comparing uncertainty analysis techniques for a SWAT application to the Chaohe Basin in China. J. Hydrol. 358 (1), 1-23.

Yatheendradas, S. et al., 2008. Understanding uncertainty in distributed flash flood forecasting for semiarid regions. Water Resour. Res. 44 (5), W05S19.

Zheng, Y., Keller, A.A., 2007. Uncertainty assessment in watershed-scale water quality modeling and management: 1. Framework and application of generalized likelihood uncertainty estimation (GLUE) approach. Water Resour. Res. 43 (8), W08407. 